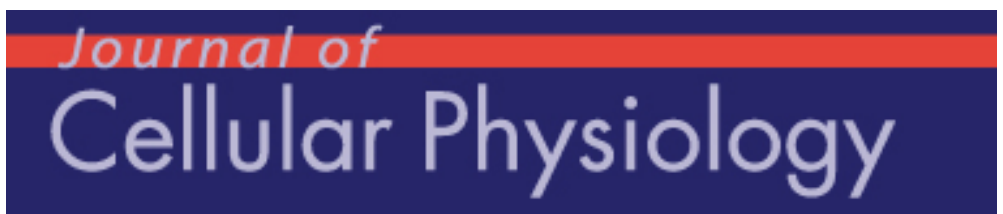

\title{
DEFICIENT MUSCLE REGENERATION POTENTIAL IN SARCOPENIC COPD PATIENTS: ROLE OF SATELLITE CELLS
}

\begin{tabular}{|c|c|}
\hline Journal: & Journal of Cellular Physiology \\
\hline Manuscript ID & Draft \\
\hline Wiley - Manuscript type: & Original Research Article \\
\hline $\begin{array}{r}\text { Date Submitted by the } \\
\text { Author: }\end{array}$ & $\mathrm{n} / \mathrm{a}$ \\
\hline Complete List of Authors: & $\begin{array}{l}\text { Sancho-Munoz, Antonio; IMIM-Hospital del Mar, Parc de Salut Mar, UPF } \\
\text { Guitart, Maria; IMIM-Hospital del Mar, Parc de Salut Mar, UPF, CIBERES } \\
\text { Rodriguez, Diego; IMIM-Hospital del Mar, Parc de Salut Mar, UPF, } \\
\text { CIBERES } \\
\text { Gea, Joaquim; IMIM-Hospital del Mar, Universitat Pompeu Fabra, } \\
\text { Barcelona Biomedical Research Park (PRBB), Respiratory Medicine } \\
\text { Martinez-Llorens, Juana; IMIM-Hospital del Mar, Parc de Salut Mar, UPF, } \\
\text { CIBERES } \\
\text { Barreiro, Esther; IMIM-Hospital del Mar, UPF, PRBB, CIBERES, } \\
\text { Pulmonology-URMAR }\end{array}$ \\
\hline Key Words: & $\begin{array}{l}\text { COPD, lower limb muscles, muscle regeneration markers, myostatin, } \\
\text { satellite cells }\end{array}$ \\
\hline
\end{tabular}

\section{SCHOLARONE \\ Manuscripts}


DEFICIENT MUSCLE REGENERATION POTENTIAL IN SARCOPENIC COPD

Antonio Sancho-Muñoz ${ }^{1}$, Maria Guitart ${ }^{1,2}$, Diego A Rodríguez ${ }^{1,2}$, Joaquim Gea ${ }^{1,2}$, Juana

4 Martínez-Llorens ${ }^{1,2}$, Esther Barreiro ${ }^{1,2}$

$5 \quad{ }^{1}$ Pulmonology Department-Muscle Wasting and Cachexia in Chronic Respiratory Diseases

6 and Lung Cancer Research Group, IMIM-Hospital del Mar, Parc de Salut Mar, Health and

7 Experimental Sciences Department (CEXS), Universitat Pompeu Fabra (UPF), Barcelona

8 Biomedical Research Park (PRBB), Dr. Aiguader, 88, E-08003 Barcelona.

$9 \quad{ }^{2}$ Centro de Investigación en Red de Enfermedades Respiratorias (CIBERES), Instituto de Salud Carlos III (ISCIII), Monforte de Lemos, 5, E-28029 Madrid.

Corresponding author: Dr. Esther Barreiro, Pulmonology Department-Pulmonology Department, Muscle Wasting \& Cachexia in Chronic Respiratory Diseases \& Lung Cancer Research Group, IMIM-Hospital del Mar, PRBB, Dr. Aiguader, 88, E-08003 Barcelona, Spain, Telephone: +3493316 0385, Fax: +34933160410, e-mail: ebarreiro@,imim.es

Short title: Muscle regeneration in COPD sarcopenia

Word count: 6,508

Data availability statement: The data sets used and/or analyzed during the current study are available from the corresponding author on reasonable request.

$\begin{array}{ll}48 & 20 \\ 9 & 21 \\ 0 & \\ 1 & \\ 2 & 22 \\ 3 & \\ 4 & 23 \\ 5 & \\ 6 & 24 \\ 7 & \\ 8 & 25 \\ 9 & 25 \\ 60 & \end{array}$

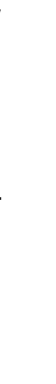




\section{ACKNOWLEDGEMENTS}

27 The authors gratefully acknowledge the help provided by MSc Kseniya Ihnatsiuk with part of 28 the molecular experiments, MSc Mireia Admetlló, Ana Balañá, and Anna Rodó for their help 29 with patient recruitment and evaluation. The current research has been supported by FIS 30 18/00075 \& CIBERES (FEDER, ISC-III), SEPAR 2018, and VIFOR Pharma 2018. 31 
32

33

\section{ABSTRACT}

Sarcopenia is a major comorbidity in COPD. Whether deficient muscle repair mechanisms and regeneration exists in vastus lateralis (VL) of sarcopenic COPD remains debatable. In vastus lateralis (VL) of control subjects and severe COPD patients with/without sarcopenia, satellite cells (SCs) were identified (immunofluorescence, specific antibodies, anti-Pax-7 and anti-Myf-5): activated (Pax-7+/Myf-5+), quiescent/regenerative potential (Pax-7+/Myf-5-), and total SCs, nuclear activation (TUNEL), and muscle fiber type (morphometry and slowand fast-twitch, and hybrid fibers), muscle damage (hematoxylin-eosin staining), muscle regeneration markers (Pax-7, Myf-5, myogenin, and MyoD), and myostatin levels were identified. Compared to controls, in VL of sarcopenic COPD patients, myostatin content, activated SCs, hybrid fiber proportions, TUNEL-positive cells, internal nuclei, and muscle damage significantly increased, while quadriceps muscle strength, numbers of Pax-7+/Myf5- and slow- and fast-twitch, and hybrid myofiber areas decreased. In VL of sarcopenic and non-sarcopenic patients, TUNEL-positive cells were greater, whereas muscle regeneration marker expression was lower than in controls. In VL of severe COPD patients regardless of the sarcopenia level, muscle regeneration process is triggered as identified by satellite cell activation and increased internal nuclei. Nonetheless, a lower regenerative potential along with significant alterations in muscle phenotype and damage, and increased myostatin were prominently seen in sarcopenic COPD.

Word count: 200

KEY WORDS: COPD; lower limb muscles; muscle regeneration markers; myostatin; satellite cells 


\section{INTRODUCTION}

Sarcopenia is a major comorbidity commonly associated with chronic respiratory diseases including COPD. The reduction of muscle mass and strength of the lower limbs differs vastly from that taking place in the respiratory muscles (Esther Barreiro, 2019; Gea \& MartínezLlorens, 2019; Gea et al., 2019; Jaitovich \& Barreiro, 2018). Sarcopenia limits the exercise capacity of the patients, thus having a negative impact on their daily-life activities and quality of life (Kwan et al., 2019; Shrikrishna et al., 2012). Furthermore, sarcopenia predicts death for the same degree of disease severity as measured by the level of the airway obstruction (Marquis et al., 2002; Swallow et al., 2007).

In the multifactorial etiology of sarcopenia associated with COPD, several clinical factors and conditions inherent to the respiratory disease, namely deconditioning, exert deleterious effects on the limb muscles through biological events and mechanisms as previously reported in relevant investigations. Most of the investigations have focused on the elucidation of factors and mechanisms primarily involved in the process of muscle mass loss in the limb muscles of the patients (E. Barreiro, Sznajder, Nader, \& Budinger, 2015; Esther Barreiro, 2019; Gea \& Martínez-Llorens, 2019; Gea et al., 2019; Jaitovich \& Barreiro, 2018) and animal models (Chacon-Cabrera et al., 2014; Chacon-Cabrera, Lund-Palau, Gea, \& Barreiro, 2016). Nonetheless, few studies have addressed the issue of the ability of the skeletal muscles to regenerate, let alone in muscles of COPD patients. The regenerative potential of a muscle will determine its capacity to regenerate following injury.

The progenitor myoblasts fuse during development to form skeletal muscles. Under normal conditions, in adult muscles, sporadic fusion of satellite cells, defined as postnatal muscle stem cells, takes place to replace the muscle turnover related to daily life activity. As skeletal muscle has the ability to regenerate following injury, regeneration of muscle tissue is a very fine regulated process in adults. The interaction between satellite cells and the 
microenvironment are the basis of muscle regeneration. As such, satellite cell numbers have been shown to be modified under specific conditions such as in aging (Suetta et al., 2013), disuse muscle atrophy (Snijders et al., 2014), prolonged bed rest (Arentson-Lantz, English, Paddon-Jones, \& Fry, 2016), and exposure to cigarette smoking (Chan et al., 2020). These modifications may alter the process of muscle regeneration in those conditions, which in turn, may coincide in patients with respiratory diseases such as in COPD.

The population of satellite cells is not homogeneous. Indeed, it has been proposed that satellite cells are heterogeneous populations of stem cells and committed progenitor cells that play different roles in the process of muscle regeneration. The activity of the skeletal muscle influenced the numbers of satellite cells in different models. For instance, aging hampered muscle regrowth following a period of disuse muscle atrophy in healthy humans (Suetta et al., 2013). In middle-aged adults, a decline in satellite cell counts was observed in the atrophic muscles following a 14-day period of bed rest (Arentson-Lantz et al., 2016). Nonetheless, changes in satellite cell counts were not detected in the quadriceps muscle of healthy young subjects following a two-week period of one-legged knee immobilization (Snijders et al., 2014).

Importantly, in the intercostal muscles of severe COPD patients, activation of satellite cells along with microstructural changes were detected (Martínez-Llorens et al., 2008). However, muscle regeneration and satellite cell counts were reduced in the vastus lateralis (VL) of patients with COPD with preserved body composition (Menon et al., 2012; M.-E. Thériault, Paré, Lemire, Maltais, \& Debigaré, 2014; M. E. Thériault, Paré, Maltais, \& Debigaré, 2012). Whether muscle regeneration events and satellite cell counts and types may differ in the lower limb muscles of patients with a different degree of disease severity and/or body composition remains to be fully elucidated.

Myostatin is a potent negative regulator of muscle mass in mammals. Myostatin keeps 
107 the quiescence of satellite cells, whereas its absence triggers activation of satellite cells.

108 Deletion of myostatin gene favors muscle mass and may lead to muscle hypertrophy (Ohno et

109 al., 2016). Moreover, myostatin blockade elicited an improvement in the regenerative

110 potential of limb muscles of mice following cardiotoxin-induced injury (Ohno et al., 2016).

111 Recently, it has also been demonstrated that myostatin plays a key role in sarcopenia and it

112 was suggested that its blockade improved muscle regeneration following injury (Scimeca et

113 al., 2017). Moreover, myostatin inhibition reduced muscle atrophy through upregulation of

114 markers involved in muscle regeneration in limb muscles of rats (Wurtzel et al., 2017).

115 On this basis, we hypothesized that the muscle regenerative potential as measured by 116 the number of stem cells and other markers of muscle regeneration may be altered in the 117 quadriceps of patients with COPD, especially in those with sarcopenia. Furthermore, protein 118 levels of the potent negative regulator of muscle regeneration myostatin were also assessed in 119 the VL of sarcopenic COPD patients. Accordingly, the study objectives were that in the 120 vastus lateralis of severe COPD patients with a wide range of body composition, including 121 those with sarcopenia, the following events were analyzed: 1) identification and counts of 122 stem cells (regenerative potential) and committed progenitors, 2) markers of muscle 123 regeneration and myostatin, and 3) muscle structural abnormalities and phenotype. A group 124 of control subjects was also recruited for the purpose of the investigation, in whom muscle 125 biopsies were also obtained and analyzed accordingly.

127 METHODS

128 Study design and population

129 This was a prospective, controlled, cross-sectional study, in which 45 patients (25 males) with 130 stable COPD (Miravitlles et al., 2017; Vogelmeier et al., 2017) were recruited consecutively 131 from the COPD clinics of the Respiratory Department at Hospital del Mar (Barcelona) over 
132 the years 2018-2019. Additionally, 13 age-matched control subjects (6 males) were recruited 133 from the general population (patients' relatives or friends) at Hospital del Mar. COPD patients 134 were further subdivided into those with and without loss of muscle mass and strength 135 (sarcopenic COPD, $n=26,11$ males and non-sarcopenic COPD, $n=19,14$ males) following the 136 international consensus criteria on muscle wasting and sarcopenia (Cao \& Morley, 2016; 137 Muscaritoli et al., 2010) and previously published criteria (Esther Barreiro, Salazar-Degracia, 138 Sancho-Muñoz, \& Gea, 2019; Puig-Vilanova, Martínez-Llorens, et al., 2015).

$140 \leq 18 \mathrm{~kg} / \mathrm{m}^{2}$, cut-off value established for a Mediterranean population in accordance with both 141 previously published criteria (Esther Barreiro et al., 2019; Puig-Vilanova, Martínez-Llorens, 142 et al., 2015) and the international consensus on the definition of sarcopenia (Cao \& Morley, 143 2016; Muscaritoli et al., 2010). Moreover, muscle weakness was defined on the basis of 144 previous investigations (approximately 25\% reduction in quadriceps force compared to that 145 observed in control subjects) (Puig-Vilanova, Martínez-Llorens, et al., 2015; Seymour et al., 146 2010). Control subjects were never-smoker male and female sedentary control individuals 147 recruited from the general population (patients' relatives or friends), while patients in both 148 groups were active smokers or ex-smokers. All patients were on inhaled bronchodilators.

149 They were clinically stable at the time of the study, without episodes of exacerbation or oral 150 steroid treatment in the previous three months. None of them presented significant 151 comorbidities. All groups of individuals were Caucasian.

152 Exclusion criteria. Exclusion criteria for COPD patients and control subjects included other 153 chronic respiratory or cardiovascular disorders, acute exacerbations in the last three months, 154 limiting osteoarticular condition, chronic metabolic diseases, suspected para-neoplastic or 155 myopathic syndromes, and/or treatment with drugs known to alter muscle structure and/or 156 function including oral corticosteroids. COPD patients and control subjects were qualified as 
157 sedentary after being specifically inquired about whether they were conducting any regular

158 outdoor physical activity, going regularly to the gymnasium, or participating in any specific

159 training program. Specifically, sedentarism was defined on the basis of the following criteria:

160 1) if subjects were not engaged in one or more of these activities: walking, running, bike

161 riding, swimming, dancing, gardening, or weight lifting more than five times per week, 2) not

162 performing at least three hours/week of endurance-type physical activity, and/or 3) inactive

163 general state in which leisure time physical activity was minimal (Ricciardi, 2006). Moreover,

164 the time spent in sedentary postures (lying and sitting) was also considered in the assessment

165 of sedentarism in the study groups (Ricciardi, 2006).

\section{Ethics}

167 The current investigation was designed in accordance with both the ethical standards on

168 human experimentation in our institution and the World Medical Association guidelines

169 (Seventh revision of the Declaration of Helsinki, Fortaleza, Brazil, 2013) (Shrestha \& Dunn,

170 2020) for research on human beings. Approval was obtained from the institutional Ethics

171 Committee on Human Investigation (Hospital del Mar-IMIM, Barcelona, project number

172 2018/7937/I). Informed written consent was obtained from both patients and control subjects.

173 Anthropometric and functional assessment

174 Anthropometric evaluation included body mass index (BMI) and determination of FFMI

175 using bioelectrical impedance (Esther Barreiro et al., 2019; Puig-Vilanova, Martínez-Llorens,

176 et al., 2015). Nutritional parameters were also evaluated through conventional blood tests.

177 Diagnostic criteria for sarcopenia were BMI $<21 \mathrm{~kg} / \mathrm{m}^{2}$ and FFMI $<18 \mathrm{~kg} / \mathrm{m}^{2}$ in all patients

178 (Esther Barreiro et al., 2019; Coin et al., 2008; Puig-Vilanova, Martínez-Llorens, et al., 2015).

179 Lung function was evaluated through determination of spirometry, static lung volumes,

180 diffusion capacity, and blood gases using standard procedures and well-established reference 
181 values (Roca, Burgos, Barberà, et al., 1998; Roca, Burgos, Sunyer, et al., 1998; Roca et al., 182 2014).

183 Quadriceps muscle strength was evaluated in both patients and controls through the 184 determination of the isometric maximum voluntary contraction (QMVC) of the dominant 185 lower limb as formerly described (Esther Barreiro et al., 2019; Puig-Vilanova, Martínez186 Llorens, et al., 2015). Briefly, patients were seated with both trunk and thigh fixed on a rigid 187 support of an exercise platform (Domyos HGH 050, Decathlon, Lille, France). The highest 188 value from three brief reproducible maneuvers ( $<5 \%$ variability among them) was accepted as 189 the QMVC.

190 Exercise capacity. Exercise capacity was assessed through the six-minute walking distance

191 following previous methodologies (Rodriguez et al., 2012). The test consisted of two attempts 192 (with at least a 30-minute rest between them) in a 30-meter corridor. Encouragement was 193 given every minute and the test was interrupted if symptoms of exhaustion appeared. A 194 modified Borg scale was used to quantify the levels of dyspnea and legs discomfort.

195 Maximum exercise capacity was also measured using standardized incremental on a 196 cycloergometer (Jones, Makrides, Hitchcock, Chypchar, \& McCartney, 1985; Rodriguez et 197 al., 2012). Pulmonary gas exchange and ventilatory measurements were obtained from 198 calibrated signals derived from rapid response gas analyzer and a mass flow sensor. Oxygen 199 uptake $\left(\mathrm{VO}_{2}\right)$, pulmonary carbon dioxide output $\left(\mathrm{VCO}_{2}\right)$, minute ventilation (VE), respiratory 200 exchange ratio (RER) were also registered during each respiration. Heart rate (HR) was 201 determined using a ten-lead online electrocardiogram and oxygen saturation by pulse 202 oximetry $\left(\mathrm{SpO}_{2}\right)$. After one minute of breathing at rest, subjects pedaled on an electrically 203 braked cycloergometer (Ergoline Ergometrix 900, Uberprüfung, Germany) (Jones et al., 1985; 204 Rodriguez et al., 2012). An integrated computer recorded cardiorespiratory variables during 
205 the test (Ultima, MedGraphics Corporation, St. Paul, MN, USA). Patients were encouraged to 206 continue until they could no longer sustain the target pedaling load.

\section{Blood samples and muscle biopsy}

208 Patients and control subjects rested for one hour on a chair with legs half-flexed, time at 209 which blood samples were obtained, after an overnight fasting period, right before initiation 210 of the surgical procedures (Esther Barreiro et al., 2019; Puig-Vilanova, Martínez-Llorens, et 211 al., 2015). Specimens from the VL portion of the quadriceps muscle (50-100 mg average 212 weight) were obtained from all subjects using the open biopsy technique as previously 213 described (Esther Barreiro et al., 2019; Puig-Vilanova, Martínez-Llorens, et al., 2015). 214 Muscle specimens were always cleaned out of any blood contamination with saline. They 215 were immediately frozen in liquid nitrogen and stored in the $-80^{\circ} \mathrm{C}$ freezer (under permanent 216 alarm control) for further analyses or immersed in an alcohol-formol bath for two hours to be 217 thereafter embedded in paraffin. Frozen tissues were used for mRNA expression and 218 immunoblotting techniques, while paraffin-embedded tissues were used for the assessment of 219 structural modifications (immunohistochemical analysis).

\section{Biological analyses}

221 Muscle fiber counts and morphometry. Myosin heavy chain (MyHC) -I and -II isoforms were 222 identified in paraffin sections (three-micrometer thick) from VL muscles corresponding to the 223 three study groups. The following antibodies were used: anti-MyHC-I (ab11083, Abcam, 224 Cambridge, UK) and anti-MyHC-II (ab51263, Abcam) antibodies. Myofibers positively 225 stained appeared in brown color. The fibers positively stained with the two antibodies 226 simultaneously were identified as the hybrid fibers. The cross-sectional area, calculated using 227 the mean least diameter, and the proportions of type I, type II and of the hybrid fibers were 228 estimated with the aid of a light microscope (Olympus BX 61, Olympus Corporation, 229 Hamburg, Germany) coupled with an image-digitizing camera (Pixera Studio, version 1.0.4, 
230 Pixera Corporation, Los Gatos, CA, USA) and a digital image processing software (ImageJ, 231 version 2006.02.01, National Institutes of Health, Bethesda, MD, USA). In all study groups, 232 the amount of fibers measured and counted in each muscle preparation ranged between 100 233 and 300 (Esther Barreiro et al., 2019; Puig-Vilanova, Martínez-Llorens, et al., 2015).

234 Muscle structure abnormalities. Three-micrometer paraffin-embedded sections from the 235 muscle specimens of the three study groups were used to assess the proportions of muscle 236 abnormalities (Esther Barreiro et al., 2019; Puig-Vilanova, Martínez-Llorens, et al., 2015). A 237 grid of 63 point-intercepts $(7 \times 9$ rectangular pattern was superimposed onto the image of the 238 muscle cross section at a magnification of x400 under the light microscope (Olympus BX 61, 239 Olympus Corporation) using an image digitizing camera (Olympus DP 71, Olympus 240 Corporation). Each point-intercept was assigned to a specific category and entered into the 241 software. Categories for point counting were defined as follows: 1) normal muscle, 2) internal 242 nucleus, 3) inflammatory cell, 4) lipofuscin, 5) abnormal viable, 6) inflamed/necrotic, 7) 243 vessel, and 0) no count. The area fraction for each category was defined as the percentage of 244 points that fell on each of these traits relative to the total number of points superimposed on 245 all viable fields (all features except for categories 0 and 7) of each cross section. The area 246 fraction of normal muscle was equivalent to the proportions of points falling in category 1 , 247 while the area fraction of abnormal muscle was determined by calculation of the proportion of 248 points included in the other categories (categories 2 to 6 ).

249 Terminal deoxynucleotidyl transferase-mediated dUTP nick-end labeling (TUNEL) assay. In 250 three-micrometer paraffin-embedded sections of muscle specimens, activation of the 251 myonuclei was determined using the TUNEL assay (ApopTag Peroxidase In Situ Apoptosis 252 Detection Kit, Merck Millipore, Burlington, United States). The manufacturer's instructions 253 and previously published studies were followed (E. Barreiro et al., 2011; Salazar-Degracia et 254 al., 2016). In brief, during nuclear activation, fragments of genomic DNA can be generated. 
255 These strand breaks in the DNA sequence can be identified by labeling 3'-OH terminal 256 groups with modified nucleotides in an enzymatic reaction catalyzed by the terminal 257 deoxynucleotidyl transferase (TdT) enzyme. Muscle sections were fixed, permeabilized and 258 immediately incubated with the TUNEL Working Strength TdT Enzyme and the anti259 Digoxigenin Conjugate. TdT catalyzed the adding of digoxigenin-dNTP at 3'-OH terminal 260 groups in single- and double-stranded DNA. After washing, the sections were incubated with 261 an anti-digoxigenin antibody conjugated with peroxidase, which resulted in brown color upon 262 reaction. Negative control experiments, in which TdT enzyme was not added, were also 263 performed. Apoptotic nuclei appeared in brown color, while negative nuclei were green 264 (methyl green counterstaining). Only nuclei located within the muscle fiber boundary were 265 counted in the study. Positive nuclei and the total number of nuclei were counted by two 266 trained observers (correlation coefficient 95\%). Apoptotic nuclei were expressed as the 267 percentage of the TUNEL-positive nuclei to the total number of counted nuclei (E. Barreiro et 268 al., 2011; Salazar-Degracia et al., 2016). A minimum of 300 nuclei were counted in each 269 muscle specimen for all the study groups.

270 Satellite cell identification using immunofluorescence microscopy. Specific antibodies were 271 used to detect quiescent, activated and total satellite cells using immunofluorescence as 272 previously described (M. Guitart, Lloreta, Mañas-Garcia, \& Barreiro, 2018). Briefly, three273 micrometer paraffin sections of the muscle specimens of all study groups were deparaffinized 274 and rehydrated by successive immersions in xylene, ethanol 100\%, ethanol $90 \%$, ethanol $70 \%$ 275 and phosphate-buffered saline (PBS). A pressure cooker containing $10 \mathrm{mM}$ citrate buffer (pH 276 6.0) was used to boil the sections for 20 minutes. Following a two-hour cooling period, 277 sections were blocked with blocking solution (3\% BSA, 10\% goat serum, and 0.5\% triton in 278 PBS) for one hour. The sections were then incubated overnight at $4^{\circ} \mathrm{C}$ with a mixture of two 279 different primary antibodies: mouse monoclonal anti-Pax-7 IgG1k supernatant (1:20; 
280 Developmental Studies Hybridoma Bank, Iowa, USA) and rabbit polyclonal anti-Myf-5 IgG 281 (1:100, AVIVA systems, San Diego, USA), prepared in blocking solution. After incubation 282 with the primary antibodies, the sections were incubated with the corresponding secondary 283 antibodies at room temperature for one hour: Alexa Fluor ${ }^{\circledR} 488$ AffiniPure goat anti-mouse 284 IgG, Fc $\gamma$ Subclass 1 Specific (1:800, Jackson Immunoresearch, West Grove, USA) and Alexa 285 Fluor ${ }^{\circledR}$ plus 555 goat anti-rabbit $\operatorname{IgG}(\mathrm{H}+\mathrm{L})$ (1:1000, Thermo Fisher Scientific, Waltham, 286 USA) respectively, which were also prepared in blocking solution along with 4',6'287 diamidino-2-phenylindole (DAPI) (1:1000). Finally, the sections were mounted using 70\% 288 glycerol in 30\% PBS. A fluorescence microscope (Nikon Eclipse Ni, Nikon, Tokyo, Japan) at 289 a magnification of $x 400$ coupled with a digitizing camera was used to count the number of 290 satellite cells. Anti-Pax-7 antibody alone was used to detect quiescent satellite cells, while the 291 combination of anti-Pax-7 and anti-Myf-5 antibodies detected committed satellite cells (M. 292 Guitart et al., 2018). The addition of quiescent and committed satellite cells corresponded to 293 the total number of satellite cells. Results are expressed as follows: 1) Pax-7+/Myf-5294 quiescent satellite cells, 2) Pax-7+/Myf-5+ activated satellite cells and 3) the addition of both 295 types of cells identified as total satellite cells. All types of fibers were normalized by the 296 number of myofibers counted within the ten fields analyzed in each muscle preparation. The 297 number of counted satellite cells ranged from 25 to 144 (quiescent), from 0 to 38 (activated), 298 and from 31 to 165 (total satellite cells) for the ten fields counted in each muscle preparation 299 in a similar fashion in the three study groups.

300 RNA isolation. Snap-frozen muscle specimens were used to isolate total RNA using Trizol 301 reagent (Life technologies, Carlsbad, California, USA). Fifty mg of muscle samples diluted in $3021 \mathrm{~mL}$ of Trizol reagent were homogenized using a T10 basic Ultra-Turrax Polytron (IKA®303 Werke GmbH \& Co. KG, Staufen, Germany) at maximum speed for 20 seconds. The 304 homogenized samples were incubated for a short period (10 minutes) at room temperature to 
305 allow the nuclear proteins to dissociate. Subsequently, $0.2 \mathrm{~mL}$ chloroform were added to the 306 samples, which were vigorously shaken manually for 15 seconds to be incubated at room 307 temperature for three minutes. The samples were centrifuged at $12,000 \mathrm{~g}$ at $4{ }^{\circ} \mathrm{C}$ for 15 308 minutes. The centrifugation process separated the homogenates into a lower red organic phase 309 and a white interphase, and a color-less upper aqueous phase. RNA content remained in the 310 aqueous phase. The RNA-containing aqueous phase was transferred to a fresh tube and the 311 RNA was precipitated by adding $0.5 \mathrm{~mL}$ isopropanol. The samples were then centrifuged at $31212,000 \mathrm{~g}$ at $4{ }^{\circ} \mathrm{C}$ for ten minutes. The pellet was kept and washed with $1 \mathrm{~mL} 75 \%$ ethanol and 313 the samples were mixed using a vortex, to be thereafter centrifuged at $7,500 \mathrm{~g}$ at $4{ }^{\circ} \mathrm{C}$ for five 314 minutes. Finally, the RNA pellet was air-dried for ten minutes and solved in RNase-free. 315 Total RNA concentrations were determined spectrophotometrically using the NanoDrop 1000 316 (Thermo Scientific, Waltham, MA, USA).

$317 m R N A$ reverse transcription (RT). Complementary DNA (cDNA) was generated from $100 \mathrm{ng}$ 318 mRNA using oligo(dT)12-18 primers, dNTP mix, DTT and the Super-Script III reverse 319 transcriptase as indicated by the manufacturer's instructions (Life Technologies, Carlsbad, 320 CA, USA). RNA was reverse-transcribed using SuperScript III reverse transcriptase and 321 oligo(dT) primers in a $20-\mu 1$ total reaction volume at $50^{\circ} \mathrm{C}$ for 60 minutes. The reverse 322 transcription reaction was finished by heating at $70^{\circ} \mathrm{C}$ for 15 minutes to stop the reaction. 323 Samples were stored at $-80^{\circ} \mathrm{C}$ until further use.

324 Quantitative real time-PCR amplification ( $q R T-P C R)$. Interestingly, qRT-PCR reactions were 325 performed using the QuantStudio 12K Flex Real-Time PCR System (Thermo Fisher 326 Scientific, Waltham, MA, USA) together with the following commercially available gene 327 expression assays: PAX3 (Hs00240950_m1, Life Technologies), PAX7 (Hs00242962_m1, 328 Life Technologies), MYF5 (Hs00929416_g1, Life Technologies), MYOD1 329 (Hs00159528_m1, Life Technologies), MYOG (Hs01072232_m1, Life Technologies), 
330 MYH7 (Hs00165276_m1, Life Technologies), MYH2 (Hs00430042_m1, Life Technologies) 331 and MYH1 (Hs00428600_m1, Life Technologies). The housekeeping gene glyceraldehyde-3332 phosphate dehydrogenase (GAPDH) (Hs99999905_m1, Life Technologies) served as the 333 endogenous control for mRNA gene expression (Table 1) (Esther Barreiro et al., 2019; M. 334 Guitart et al., 2018; Puig-Vilanova, Martínez-Llorens, et al., 2015). Duplicates from all 335 samples were run and the average value was calculated for each study sample. The results 336 obtained from the experiments were collected and analyzed using the ExpressionSuite 337 Software version 1.1 from Applied Biosystems (Thermo Fisher Scientific, Waltham, MA, 338 USA), in which the comparative CT method (2- $\Delta \Delta \mathrm{CT})$ for relative quantification was used as 339 previously reported (Maria Guitart, Lloreta, Mañas-Garcia, \& Barreiro, 2018; Livak \& 340 Schmittgen, 2001).

341 Immunoblotting. Protein levels of myostatin were analyzed using immunoblotting procedures 342 as previously described (Esther Barreiro et al., 2019; M. Guitart et al., 2018; Puig-Vilanova, 343 Martínez-Llorens, et al., 2015). Briefly, frozen samples from all experimental groups were 344 homogenized in lysis buffer: $50 \mathrm{mM}$ HEPES, $150 \mathrm{mM} \mathrm{NaCl}, 100 \mathrm{mM} \mathrm{NaF}, 10 \mathrm{mM} \mathrm{Na}$ 345 pyrophosphate, $5 \mathrm{mM}$ EDTA, $10 \%$ glycerol, $0.5 \%$ Triton-X, $5 \mu \mathrm{g} / \mathrm{mL}$ aprotinin, $2 \mu \mathrm{g} / \mathrm{mL}$ 346 leupeptin, $100 \mu \mathrm{g} / \mathrm{mL}$ PMSF, and $10 \mu \mathrm{g} / \mathrm{mL}$ pepstatin A.

347 Proteins were separated by electrophoresis, transferred to polyvinylidene difluoride (PVDF) 348 membranes, blocked with bovine serum albumin (BSA) and incubated overnight with the 349 corresponding primary antibody: Myostatin (anti-GDG8, Bethyl Laboratories, Montgomery, 350 USA) and the endogenous control glyceraldehyde-3-phosphate dehydrogenase (GAPDH) 351 (anti-GAPDH antibody, Santa Cruz Biotechnology).

352 Antigens from all samples were detected with horseradish peroxidase (HRP)-conjugated 353 secondary antibodies and a chemiluminescence kit. For each of the antigens, samples from the 354 different groups were always detected in the same picture under identical exposure times. 
355 PVDF membranes were scanned with the Molecular Imager Chemidoc XRS System (Bio356 Rad Laboratories, Hercules, CA, USA) using the software Quantity One version 4.6.5 (Bio357 Rad Laboratories). Optical densities of specific proteins were quantified using the software 358 Image Lab version 2.0.1 (Bio-Rad Laboratories). Final optical densities obtained in each 359 specific group of subjects and muscle corresponded to the mean values of the different 360 samples (lanes) of each of the antigens studied. In order to validate equal protein loading 361 among various lanes, the glycolytic enzyme GAPDH was used as the protein loading controls 362 in all the immunoblots.

363 Myostatin identification using immunohistochemical procedures. Myostatin was identified in 364 paraffin sections (three-micrometer thick) from VL muscles corresponding to the three study 365 groups using conventional immunohistochemical procedures as previously described (Puig366 Vilanova, Martínez-Llorens, et al., 2015; Puig-Vilanova, Rodriguez, et al., 2015). Following 367 deparaffinization, a pressure cooker containing $10 \mathrm{mM}$ citrate buffer ( $\mathrm{pH}$ 6.0) was used to boil 368 the sections for 20 minutes. Following a two-hour cooling period, sections were blocked with $3696 \%$ hydrogen peroxide for 15 min and with a blocking solution (3\% BSA, 10\% goat serum, 370 and $0.5 \%$ triton in PBS) for one hour. The sections were then incubated overnight at $4^{\circ} \mathrm{C}$ with 371 the primary antibody: Myostatin (anti-GDG8, Bethyl Laboratories). Slides were then 372 incubated with universal secondary antibody (polystain-1 step kit, HRP for DBA, mouse and 373 rabbit, Neo Biotech, Nanterre, France) for 30 minutes, followed by incubation with the 374 substrate diaminobenzidine (DAB) (DAB kit, Neo Biotech) for five minutes. Hematoxylin 375 counterstaining was performed, and slides were dehydrated and mounted for conventional 376 microscopy. Images of the stained muscle sections were captured with a light microscope 377 (Olympus BX 61, Olympus Corporation) coupled with an image-digitizing camera (Pixera 378 Studio, version 1.0.4, Pixera Corporation).

379 Statistical Analysis 
380 Normality of the study variables was checked using the Shapiro-Wilk test. All the results are 381 expressed as mean (standard deviation). For the quantitative variables, one-way analysis of 382 variance (ANOVA) with Tukey's post hoc analysis was used to adjust for multiple 383 comparisons among the study groups. For the qualitative variables (smoking history), $\chi^{2}$ test 384 was used to assess differences among the three study groups. A level of significance of $\mathrm{P} \leq$ $385 \quad 0.05$ was established.

\section{$387 \quad$ RESULTS}

\section{Functional and nutritional status of the study subjects}

389 Body composition as measured by BMI and FFMI was significantly reduced in sarcopenic

390 COPD patients compared to non-sarcopenic controls and control subjects (Table 2). Smoking 391 history including the number of packs-year was similar in both groups of COPD patients and 392 significantly differed from that of the controls (never smokers, Table 2). As expected, both 393 groups of COPD patients exhibited severe airflow limitation and a decline in diffusion 394 capacity, especially the sarcopenic patients (Table 2). Moreover, compared to control 395 subjects, exercise tolerance was significantly reduced in both groups of COPD patients, 396 whereas quadriceps muscle strength was significantly lower only in the sarcopenic patients 397 compared to both non-sarcopenic and control subjects (Table 2). Nutritional blood parameters 398 including CRP did not significantly differ among the three study groups of subjects, while 399 fibrinogen levels were significantly greater in both groups of COPD patients than in the 400 controls (Table 2).

\section{Muscle phenotype and damage}

402 The proportions of slow-twitch muscle fibers were significantly lower in the VL of the 403 sarcopenic COPD patients than in the control subjects, while those of the hybrid fibers 404 increased in the limb muscles of both groups of COPD patients (Figure 1A and Table 3). 
405 Furthermore, the proportions of hybrid fibers were significantly greater in the lower limb 406 muscles of the sarcopenic patients than in non-sarcopenic patients (Figure 1A and Table 3).

407 Compared to the controls, the cross-sectional area of slow-twitch fibers was significantly 408 reduced in the VL of both groups of COPD patients. Furthermore, the size of both fast-twitch 409 and hybrid fibers was significantly smaller in muscles of the sarcopenic patients than in both 410 control subjects and non-sarcopenic patients (Figure 1A and Table 3). The proportions of 411 muscle structural abnormalities and internal nuclei counts were significantly greater in the VL 412 of both groups of COPD patients than in control subjects (Figure 1B). Besides, muscle 413 structural abnormalities were also significantly greater in the VL of sarcopenic than in non414 sarcopenic COPD patients (Figure 1B). Interestingly, the number of TUNEL-positive nuclei 415 was significantly increased in the VL of both groups of COPD patients compared to those in 416 the control subjects (Figures 2A and 2B). Among all COPD patients, significant correlations 417 were detected between muscle phenotype variables (proportions of slow- and fast-twitch 418 fibers and CSA of type I fibers) and lung function parameters (degree of airway obstruction 419 and diffusion capacity, respectively, Table 4A). Among the COPD patients, significant 420 positive correlations were also detected between CSA of slow and fast-twitch fibers and 421 hybrid fibers and FFMI (Table 4A). Furthermore, among all COPD patients as a whole, 422 quadriceps strength significantly correlated with TUNEL-positive nuclei and muscle 423 abnormalities (Table 4A).

\section{Satellite cells in muscles of COPD patients}

425 The number of quiescent satellite cells as measured by Pax-7+/Myf-5- cells was significantly 426 lower only in VL of the sarcopenic COPD patients than in the control subjects (Figures 3A 427 and 3B). Counts of activated satellite cells (Pax-7+/ Myf-5+) were significantly greater in the 428 VL of both groups of COPD patients than in control subjects (Figures 3A and 3B). Numbers 429 of total satellite cells did not significantly differ among the three study groups (Figures $3 \mathrm{~A}$ 
430 and 3B). Besides, among all COPD patients as a whole, the number of muscle activated 431 satellite cells inversely correlated with plasma levels of CRP (Table 4A). Specifically, in VL 432 of sarcopenic COPD patients, expression levels of PAX7 and MYOD significantly correlated 433 with the degree of airway obstruction (Table 4B). Moreover, in the same muscles, proportions 434 of slow-twitch fibers significantly correlated with the lung function parameters $\mathrm{FEV}_{1} / \mathrm{FVC}$ 435 and DLco (Table 4B).

\section{Expression of muscle regeneration and regulatory markers in COPD patients}

437 Gene expression levels of the regeneration markers Pax-7 and Myf-5 (proliferation phase) and 438 MyoD and MyHCI (differentiation phase) were significantly reduced in the VL of both 439 groups of COPD patients compared to the control subjects (Figure 4A). Protein expression 440 levels of myostatin significantly increased in the VL of the sarcopenic patients compared to 441 both control subjects and non-sarcopenic COPD patients (Figure 4B and 4C). The expression 442 of MyHCIIx was significantly upregulated only in the VL of the sarcopenic COPD patients 443 compared to the control subjects (Figure 4A).

\section{DISCUSSION}

446 In this investigation, the most relevant findings were that in sarcopenic COPD patients with 447 preserved nutritional status and decreased exercise capacity, muscle strength was, indeed, 448 significantly reduced and in the VL of these patients, a significant decline in muscle 449 regeneration potential as measured by the number of Pax-7+/Myf-5- satellite cells, a decrease 450 in slow-twitch fiber type proportions and in the size of both fast-twitch and hybrid fibers, 451 along with a significant rise in both hybrid fibers proportions and muscle structural 452 abnormalities were observed. Importantly, in the limb muscles of both groups of COPD 453 patients, the numbers of internal nuclei, activated satellite cells (Pax-7+/Myf-5+), and 454 TUNEL-positive nuclei were significantly greater than in the controls, while the expression of 
455 markers of early (proliferation phase, Pax-7 and Myf-5) and late (differentiation phase, MyoD 456 and MyHCI) muscle regeneration was downregulated. Levels of the potent negative regulator 457 myostatin increased only in the limb muscles of the sarcopenic COPD patients. Collectively, 458 these findings suggest that markers of regenerative potential in the limb muscles of sarcopenic 459 COPD patients is reduced and myostatin may play a significant role. Moreover, as the rise in 460 muscle damage levels were detected to a greater extent in the VL of the sarcopenic COPD 461 patients (64\% greater than in control muscles), such structural alterations are also likely to be 462 involved in the triggering of the muscle regeneration process (Cheung \& Rando, 2013; Yin, 463 Price, \& Rudnicki, 2013). The most relevant results are discussed below.

464 Previous investigations have shown that the number of central nuclei, a marker of 465 muscle regeneration, and those of senescent satellite cells were increased in lower limb 466 muscles of COPD patients with different degrees of body composition (M.-E. Thériault et al., 467 2014; M. E. Thériault et al., 2012).

468 Among COPD patients, significant correlations were observed between lung function 469 parameters, especially airway obstruction and diffusion capacity and the proportions of slow470 twitch fibers, and patients with better lung function parameters were those with a higher 471 proportion of type I fibers. Conversely, proportions and size of type II fibers inversely 472 correlated with the degree of airway obstruction and diffusion capacity. These are relevant 473 findings that suggest that lung function partly contributes to the slow-to-fast fiber type switch 474 in the lower limb muscles of COPD patients as also previously implied (Esther Barreiro et al., 475 2018; Puig-Vilanova, Martínez-Llorens, et al., 2015; Puig-Vilanova, Rodriguez, et al., 2015). 476 Furthermore, the size of slow- and fast-twitch fibers and that of hybrid fibers also correlated 477 with FFMI, suggesting that lean body mass was associated with a greater CSA of all the 478 muscle fiber types among the COPD patients. In addition, muscle damage and internal nuclei 479 counts were also inversely correlated with isometric strength of the quadriceps muscle of all 
480 the COPD patients. Collectively, these are relevant novel findings that indicate that muscle 481 structure and function are clearly interrelated and should be assessed on routine basis in 482 COPD patient clinics, especially in patients with alterations in their body composition. 483 Another interesting finding in the study was the negative correlation found between CRP 484 plasma levels and the number of activated satellite cells. These results illustrate that systemic 485 inflammation as measured by CRP somehow influenced the process of muscle regeneration as 486 also implied to occur in muscles of COPD patients (Ioannis Vogiatzis et al., 2007).

In the current investigation, a relatively large number of sarcopenic COPD patients of 488 a fairly "young age", with a significant decline in quadriceps muscle function, preserved 489 nutritional status, and altered body composition were carefully recruited. With the aim to 490 elucidate whether muscle regeneration potential may be hampered in the lower limb muscles 491 of sarcopenic COPD patients, two different phenotypes of satellite cells were determined in 492 the present study. As previously characterized (Kuang, Kuroda, Le Grand, \& Rudnicki, 2007), 493 sublaminar satellite cells that express Pax-7 but do not express Myf-5 constitute the satellite 494 cell reservoir of a given muscle. In that seminal investigation (Kuang et al., 2007), it was 495 clearly demonstrated that Pax-7+/Myf-5+ satellite cells preferentially differentiate into muscle 496 fibers, whereas Pax-7+/Myf-5- satellite cells contribute to the satellite cell reservoir enlarging 497 this compartment within skeletal muscle. The conclusions from that study (Kuang et al., 498 2007) were that two different subpopulations of satellite cells were established on the basis of 499 their ability to express Myf-5 (Kuang et al., 2007). As such Pax-7+/Myf-5+ satellite cells 500 were identified as the committed myogenic progenitors, while Pax-7+/Myf-5- satellite cells 501 were defined as the actual stem cells (Kuang et al., 2007). Importantly, in the present investigation, a significant decline in the number of Pax503 7+/Myf-5- satellite cells was detected only in the limb muscles of the sarcopenic COPD 504 patients, but not in those with preserved body composition and normal quadriceps muscle 
505 function. These findings imply that the satellite cell reservoir was hampered in the sarcopenic 506 muscles, which may further jeopardize the process of muscle regeneration. In fact, the 507 proportions of slow-twitch muscle fibers were reduced only in the VL of the sarcopenic 508 COPD patients. Moreover, the size of slow-twitch, fast-twitch, and hybrid myofibers was also 509 significantly smaller in the lower limb muscles of the sarcopenic patients, but not in those 510 with preserved body composition. Additionally, muscle structural abnormalities were even 511 greater in the VL of the sarcopenic COPD patients than in those with no muscle loss. These 512 results, which are very consistent with those obtained in previous investigations (Esther 513 Barreiro et al., 2019; Puig-Vilanova, Martínez-Llorens, et al., 2015; Puig-Vilanova, 514 Rodriguez, et al., 2015), may be partly explained by the poorer regenerative potential detected 515 in the limb muscles of the sarcopenic patients. Proportions of hybrid fibers increased in the 516 limb muscles of both groups of COPD patients and the proportions were even greater in the 517 VL of the sarcopenic patients than in the non-sarcopenic group, while their CSA was smaller 518 in the former patients. These are relevant findings that imply that muscles of COPD patients, 519 especially of the sarcopenic ones, are able to adapt to environmental factors such as inactivity, 520 exercise, or aging (Medler, 2019). Collectively, these events are of paramount importance, 521 since a correct muscle regeneration program is required in order to attain full recovery of 522 muscle mass and function in response to different training modalities. Thus, the current 523 results have potential clinical implications for the design of specific exercise training 524 programs as patients with a defective regenerative potential may be less susceptible to 525 improving their muscle mass and/or function even those with preserved nutritional status. It is worth noting that the lower limb muscles of both groups of COPD patients 527 experienced the activation of a muscle regeneration program in a similar fashion. In line with 528 this, the number of specific activated satellite cells (Pax-7+/Myf-5+), internal nuclei, and TUNEL-positive nuclei were notably and similarly increased in the VL of both groups of 
530 severe COPD patients compared to those detected in the control muscles. These findings are

531 in line with previous results, in which the process of muscle regeneration was also triggered in 532 the VL of severe COPD patients with a wide range of muscle mass loss (M.-E. Thériault et 533 al., 2014; M. E. Thériault et al., 2012). However, in another study (Menon et al., 2012), the 534 number of satellite cells was similar between COPD patients and healthy controls at baseline. 535 Differences in the level of alterations in body composition compartments and/or muscle 536 function and mass may account for discrepancies encountered among studies (Menon et al., 537 2012; M.-E. Thériault et al., 2014; M. E. Thériault et al., 2012). Furthermore, gene expression levels of the early markers of muscle regeneration Pax-7 539 and Myf-5 were downregulated in the VL of both groups of severe COPD patients compared 540 to the controls. Pax-7 and Myf-5 transcription factors play key roles during the proliferation 541 phase of the muscle regeneration process (M. Guitart et al., 2018; Yin et al., 2013). In keeping 542 with, similar results were also reported in the quadriceps muscle of cachectic COPD patients 543 (Plant et al., 2010; M.-E. Thériault et al., 2014; M. E. Thériault et al., 2012). The 544 downregulation in gene expression of the transcription factors MyoD and Myogenin and of 545 MyHC-I isoform as markers of late muscle differentiation during the regeneration process 546 was another relevant finding in the investigation. These findings are also in line with those 547 previously demonstrated in muscles of patients with advanced COPD (Plant et al., 2010; 548 Puig-Vilanova, Martínez-Llorens, et al., 2015; M.-E. Thériault et al., 2014; M. E. Thériault et 549 al., 2012).

550 Myostatin, a member of the transforming growth factor beta family, is a negative 551 regulator of muscle growth. Myostatin is also known to inhibit satellite cell and myoblast 552 proliferation through several mechanisms that lead to cell cycle withdrawal (Walsh \& Celeste, 553 2005). Importantly, myostatin levels were significantly greater in the limb muscles of the 554 sarcopenic patients than those detected within the non-sarcopenic patients or the control 
555 subjects. These results are line with previous studies, in which myostatin levels were 556 consistently demonstrated to rise in the lower limb muscles of patients with advanced COPD 557 (Harish et al., 2019; Plant et al., 2010; Puig-Vilanova, Martínez-Llorens, et al., 2015; Walsh $558 \&$ Celeste, 2005). In view of all these findings, it would possible to conclude that myostatin 559 may have interfered with the process of muscle cell proliferation early on during the 560 regeneration process, thus leading to poor muscle growth and development following injury. 561 Hence, this may be another mechanism of muscle mass loss in addition to increased 562 proteolysis and/or apoptosis as also consistently shown in previous investigations (Plant et al., 563 2010; Puig-Vilanova, Martínez-Llorens, et al., 2015; I Vogiatzis et al., 2010). Nonetheless, 564 elucidation of the precise role and implications of myostatin on muscle regeneration and 565 growth in COPD sarcopenia will have to be definitively confirmed in future investigations.

566 On the other hand, the reported findings may also have future clinical implications as 567 myostatin blockade using specific antibodies has been shown to partly revert the loss of 568 muscle mass and function in several experimental models (Harish et al., 2019; Iskenderian et 569 al., 2018; St. Andre et al., 2017) and in patients (Burch et al., 2017; Scimeca et al., 2017). 570 Whether anti-myostatin antibodies can also be effectively used in patients with non-muscle 571 diseases such as in sarcopenic COPD will be the matter of research in future investigations. 572 This will shed more light into the implications of myostatin in the muscle regenerative 573 capacity of sarcopenic COPD patients.

\section{Conclusions}

575 In the lower limb muscles of severe COPD patients regardless of the degree of sarcopenia, 576 muscle regeneration process is triggered as identified by satellite cell activation and a rise in 577 internal nuclei counts. Nonetheless, the regenerative potential along with significant 578 alterations in muscle phenotype (slow-to-fast switch phenotype and smaller fast-twitch and 579 hybrid myofibers) and muscle damage were prominently seen in the sarcopenic COPD. A rise 
580 in the muscle growth inhibitor myostatin was also detected only in the VL of the sarcopenic

581 COPD patients, which may further aggravate loss of muscle mass and function in this specific 582 group of patients. These findings have clinical implications as not all COPD patients may 583 equally respond to exercise and/or muscle training modalities and myostatin blockade should 584 be specifically customized to patients with sarcopenia in COPD.

585

586

587 
588 Authors' contributions: Study conception and design: EB, ASM, JMLL; Patient assessment 589 and recruitment and sample collection: ASM, JMLL; Molecular biology analyses: MG; 590 Statistical analyses and data interpretation: MG, ASM, EB; manuscript drafting and 591 intellectual input: EB, ASM, MG, JG, JMLL, DAR; manuscript writing final version: EB.

\section{Ethical publication statement}

593 We confirm that we have read the Journal's position on issues involved in ethical publication 594 and affirm that this report is consistent with those guidelines

595 Disclosure of conflict of interest

596 None of the authors has any conflict of interest to disclose

\section{Editorial support}

598 None to declare

599 


\section{REFERENCES}

601 Arentson-Lantz, E. J., English, K. L., Paddon-Jones, D., \& Fry, C. S. (2016). Fourteen days of 602 bed rest induces a decline in satellite cell content and robust atrophy of skeletal muscle 603 fibers in middle-aged adults. Journal of Applied Physiology, 120(8), 965-975. $604 \quad$ https://doi.org/10.1152/japplphysiol.00799.2015

605 Barreiro, E. (2019). Impact of Physical Activity and Exercise on Chronic Obstructive 606 Pulmonary Disease Phenotypes: The Relevance of Muscle Adaptation. Archivos de 607 Bronconeumologia. https://doi.org/10.1016/j.arbres.2019.04.024

608 Barreiro, E., Ferrer, D., Sanchez, F., Minguella, J., Marin-Corral, J., Martinez-Llorens, J., ... 609 Gea, J. (2011). Inflammatory cells and apoptosis in respiratory and limb muscles of 610 patients with COPD. Journal of Applied Physiology, 111(3). https://doi.org/10.1152/japplphysiol.01017.2010

612 Barreiro, E., Puig-Vilanova, E., Salazar-Degracia, A., Pascual-Guardia, S., Casadevall, C., \& 613 Gea, J. (2018). The phosphodiesterase-4 inhibitor roflumilast reverts proteolysis in 614 skeletal muscle cells of patients with COPD cachexia. Journal of Applied Physiology, 615 125(2), 287-303. https://doi.org/10.1152/japplphysiol.00798.2017

616 Barreiro, E., Salazar-Degracia, A., Sancho-Muñoz, A., \& Gea, J. (2019). Endoplasmic 617 reticulum stress and unfolded protein response profile in quadriceps of sarcopenic 618 patients with respiratory diseases. Journal of Cellular Physiology, 234(7), 11315-11329. 619 https://doi.org/10.1002/jcp.27789

620 Barreiro, E., Sznajder, J. I., Nader, G. A., \& Budinger, G. R. S. (2015). Muscle dysfunction in 621 patients with lung diseases a growing epidemic. American Journal of Respiratory and 622 Critical Care Medicine, 191(6). https://doi.org/10.1164/rccm.201412-2189OE (2017). Reduced serum myostatin concentrations associated with genetic muscle disease 
625

626

627

628

629

630

631

632

633

634

635

636

637

638

639

640

641

642

643

644

645

646

647

648

649

progression. Journal of Neurology, 264(3), 541-553. https://doi.org/10.1007/s00415016-8379-6

Cao, L., \& Morley, J. E. (2016, August 1). Sarcopenia Is Recognized as an Independent Condition by an International Classification of Disease, Tenth Revision, Clinical Modification (ICD-10-CM) Code. Journal of the American Medical Directors Association, Vol. 17, pp. 675-677. https://doi.org/10.1016/j.jamda.2016.06.001

Chacon-Cabrera, A., Fermoselle, C., Urtreger, A. J., Mateu-Jimenez, M., Diament, M. J., de Kier Joffé, E. D. B., ... Barreiro, E. (2014). Pharmacological Strategies in Lung CancerInduced Cachexia: Effects on Muscle Proteolysis, Autophagy, Structure, and Weakness. Journal of Cellular Physiology, 229(11). https://doi.org/10.1002/jcp.24611

Chacon-Cabrera, A., Lund-Palau, H., Gea, J., \& Barreiro, E. (2016). Time-Course of muscle mass loss, damage, and proteolysis in gastrocnemius following unloading and reloading: Implications in chronic diseases. PLoS ONE, 11(10). https://doi.org/10.1371/journal.pone.0164951

Chan, S. M. H., Cerni, C., Passey, S., Seow, H. J., Bernardo, I., van der Poel, C., ... Vlahos, R. (2020). Cigarette Smoking Exacerbates Skeletal Muscle Injury without Compromising Its Regenerative Capacity. American Journal of Respiratory Cell and Molecular Biology, 62(2), 217-230. https://doi.org/10.1165/rcmb.2019-0106OC

Cheung, T. H., \& Rando, T. A. (2013, June). Molecular regulation of stem cell quiescence. Nature Reviews Molecular Cell Biology, Vol. 14, pp. 329-340. https://doi.org/10.1038/nrm3591

Coin, A., Sergi, G., Minicuci, N., Giannini, S., Barbiero, E., Manzato, E., ... Enzi, G. (2008). Fat-free mass and fat mass reference values by dual-energy X-ray absorptiometry (DEXA) in a 20-80 year-old Italian population. Clinical Nutrition, 27(1), 87-94. https://doi.org/10.1016/j.clnu.2007.10.008 
650 Gea, J., \& Martínez-Llorens, J. (2019). Muscle Dysfunction in Chronic Obstructive

651 Pulmonary Disease: Latest Developments. Archivos de Bronconeumologia, 55(5), 237652 238. https://doi.org/10.1016/j.arbres.2018.07.016

653 Gea, J., Pascual, S., Castro-Acosta, A., Hernández-Carcereny, C., Castelo, R., Márquez654 Martín, E., ... Anexo. Miembros del grupo BIOMEPOC. (2019). The BIOMEPOC 655 Project: Personalized Biomarkers and Clinical Profiles in Chronic Obstructive 656 Pulmonary Disease. Archivos de Bronconeumologia, 55(2), 93-99. 657 https://doi.org/10.1016/j.arbres.2018.07.026

658 Guitart, M., Lloreta, J., Mañas-Garcia, L., \& Barreiro, E. (2018). Muscle regeneration 659 potential and satellite cell activation profile during recovery following hindlimb 660 immobilization in mice. Journal of Cellular Physiology, 233(5). 661 https://doi.org/10.1002/jcp.26282

662 Guitart, M., Lloreta, J., Mañas-Garcia, L., \& Barreiro, E. (2018). Muscle regeneration 663 potential and satellite cell activation profile during recovery following hindlimb 664 immobilization in mice. Journal of Cellular Physiology, 233(5), 4360-4372. 665 https://doi.org/10.1002/jcp.26282

666 Harish, P., Malerba, A., Lu-Nguyen, N., Forrest, L., Cappellari, O., Roth, F., ... Dickson, G. 667 (2019). Inhibition of myostatin improves muscle atrophy in oculopharyngeal muscular 668 669 dystrophy (OPMD). Journal of Cachexia, Sarcopenia and Muscle, 10(5), 1016-1026. https://doi.org/10.1002/jcsm. 12438

670 Iskenderian, A., Liu, N., Deng, Q., Huang, Y., Shen, C., Palmieri, K., ... Ehmann, D. E. 671 (2018). Myostatin and activin blockade by engineered follistatin results in hypertrophy 672 and improves dystrophic pathology in mdx mouse more than myostatin blockade alone. $673 \quad$ Skeletal Muscle, 8(1). https://doi.org/10.1186/s13395-018-0180-z

674 Jaitovich, A., \& Barreiro, E. (2018). Skeletal muscle dysfunction in chronic obstructive 
675

676

677

678

679

680

681

682

683

684

685

686

687

688

689

690

691

692

693

694

695

696

697

698

699

pulmonary disease what we know and can do for our patients. American Journal of Respiratory and Critical Care Medicine, 198(2). https://doi.org/10.1164/rccm.201710$2140 \mathrm{CI}$

Jones, N. L., Makrides, L., Hitchcock, C., Chypchar, T., \& McCartney, N. (1985). Normal standards for an incremental progressive cycle ergometer test. American Review of Respiratory Disease, 131(5), 700-708. https://doi.org/10.1164/arrd.1985.131.5.700

Kuang, S., Kuroda, K., Le Grand, F., \& Rudnicki, M. A. (2007). Asymmetric self-renewal and commitment of satellite stem cells in muscle. Cell, 129(5), 999-1010. https://doi.org/10.1016/j.cell.2007.03.044

Kwan, H. Y., Maddocks, M., Nolan, C. M., Jones, S. E., Patel, S., Barker, R. E., ... Man, W. D. C. (2019). The prognostic significance of weight loss in chronic obstructive pulmonary disease-related cachexia: a prospective cohort study. Journal of Cachexia, Sarcopenia and Muscle, 10(6), 1330-1338. https://doi.org/10.1002/jcsm.12463

Livak, K. J., \& Schmittgen, T. D. (2001). Analysis of relative gene expression data using realtime quantitative PCR and the 2- $\Delta \Delta \mathrm{CT}$ method. Methods, 25(4), 402-408. https://doi.org/10.1006/meth.2001.1262

Marquis, K., Debigaré, R., Lacasse, Y., LeBlanc, P., Jobin, J., Carrier, G., \& Maltais, F. (2002). Midthigh muscle cross-sectional area is a better predictor of mortality than body mass index in patients with chronic obstructive pulmonary disease. American Journal of Respiratory and Critical Care Medicine, 166(6), 809-813. https://doi.org/10.1164/rccm.2107031

Martínez-Llorens, J., Casadevall, C., Lloreta, J., Orozco-Levi, M., Barreiro, E., Broquetas, J., \& Gea, J. (2008). [Activation of satellite cells in the intercostal muscles of patients with chronic obstructive pulmonary disease]. Archivos de Bronconeumologia, 44(5), 239244. Retrieved from http://www.ncbi.nlm.nih.gov/pubmed/18448014 
700 Medler, S. (2019, November 29). Mixing it up: The biological significance of hybrid skeletal 701 702

Miravitlles, M., Soler-Cataluña, J. J., Calle, M., Molina, J., Almagro, P., Quintano, J. A., ... Ancochea, J. (2017). Spanish Guidelines for Management of Chronic Obstructive Pulmonary Disease (GesEPOC) 2017. Pharmacological Treatment of Stable Phase. Archivos de Bronconeumologia, 53(6), 324-335. https://doi.org/10.1016/j.arbres.2017.03.018

Muscaritoli, M., Anker, S. D., Argilés, J., Aversa, Z., Bauer, J. M., Biolo, G., ... Sieber, C. C. (2010). Consensus definition of sarcopenia, cachexia and pre-cachexia: Joint document elaborated by Special Interest Groups (SIG) “ cachexia-anorexia in chronic wasting diseases" and " nutrition in geriatrics." Clinical Nutrition, 29(2), 154-159. https://doi.org/10.1016/j.clnu.2009.12.004

Ohno, Y., Matsuba, Y., Hashimoto, N., Sugiura, T., Ohira, Y., Yoshioka, T., \& Goto, K. (2016). Suppression of myostatin stimulates regenerative potential of injured antigravitational soleus muscle in mice under unloading condition. International Journal of Medical Sciences, 13(9), 680-685. https://doi.org/10.7150/ijms.16267

Plant, P. J., Brooks, D., Faughnan, M., Bayley, T., Bain, J., Singer, L., ... Batt, J. (2010). Cellular markers of muscle atrophy in chronic obstructive pulmonary disease. American Journal of Respiratory Cell and Molecular Biology, 42(4), 461-471. https://doi.org/10.1165/rcmb.2008-0382OC 
725 Puig-Vilanova, E., Martínez-Llorens, J., Ausin, P., Roca, J., Gea, J., \& Barreiro, E. (2015).

726 Quadriceps muscle weakness and atrophy are associated with a differential epigenetic 727 profile in advanced COPD. Clinical Science, 128(12).

$728 \quad$ https://doi.org/10.1042/CS20140428

729 Puig-Vilanova, E., Rodriguez, D. A., Lloreta, J., Ausin, P., Pascual-Guardia, S., Broquetas, J., $730 \quad$... Barreiro, E. (2015). Oxidative stress, redox signaling pathways, and autophagy in 731 cachectic muscles of male patients with advanced COPD and lung cancer. Free Radical 732 Biology and Medicine, 79. https://doi.org/10.1016/j.freeradbiomed.2014.11.006

733 Ricciardi, R. (2006). Sedentarism: a concept analysis. Nursing Forum, 40(3), 79-87. 734 https://doi.org/10.1111/j.1744-6198.2005.00021.x

735 Roca, J., Burgos, F., Barberà, J. A., Sunyer, J., Rodriguez-Roisin, R., Castellsagué, J., ... 736 Clausen, J. L. (1998). Prediction equations for plethysmographic lung volumes. 737 Respiratory Medicine, 92(3), 454-460. https://doi.org/10.1016/s0954-6111(98)90291-8 738 Roca, J., Burgos, F., Sunyer, J., Saez, M., Chinn, S., Antó, J. M., ... Burney, P. (1998). 739 References values for forced spirometry. Group of the European Community Respiratory $740 \quad$ Health Survey. The European Respiratory Journal, 11(6), 1354-1362. Retrieved from 741 http://www.ncbi.nlm.nih.gov/pubmed/9657579

742 Roca, J., Vargas, C., Cano, I., Selivanov, V., Barreiro, E., Maier, D., ... Gomez-Cabrero, D. 743 (2014). Chronic Obstructive Pulmonary Disease heterogeneity: Challenges for health 744 risk assessment, stratification and management. Journal of Translational Medicine, 12. 745 https://doi.org/10.1186/1479-5876-12-S2-S3

746 Rodriguez, D. A., Kalko, S., Puig-Vilanova, Ø., Perez-Olabarría, M., Falciani, F., Gea, J., ... 747 Roca, J. (2012). Muscle and blood redox status after exercise training in severe COPD $748 \quad$ patients. Free Radical Biology and Medicine, 52(1), 88-94.

749 https://doi.org/10.1016/j.freeradbiomed.2011.09.022 
750 Salazar-Degracia, A., Blanco, D., Vilà-Ubach, M., Biurrun, G., Solórzano, C. O., Montuenga, 751 L. M., \& Barreiro, E. (2016). Phenotypic and metabolic features of mouse diaphragm

and gastrocnemius muscles in chronic lung carcinogenesis: Influence of underlying emphysema. Journal of Translational Medicine, 14(1). https://doi.org/10.1186/s12967016-1003-9

Scimeca, M., Piccirilli, E., Mastrangeli, F., Rao, C., Feola, M., Orlandi, A., ... Tarantino, U. (2017). Bone Morphogenetic Proteins and myostatin pathways: Key mediator of human sarcopenia. Journal of Translational Medicine, 15(1). https://doi.org/10.1186/s12967017-1143-6

Seymour, J. M., Spruit, M. A., Hopkinson, N. S., Natanek, S. A., Man, W. D.-C., Jackson, A., ... Wouters, E. F. M. (2010). The prevalence of quadriceps weakness in COPD and the relationship with disease severity. The European Respiratory Journal, 36(1), 81-88. https://doi.org/10.1183/09031936.00104909

Shrestha, B., \& Dunn, L. (2020). The Declaration of Helsinki on Medical Research involving Human Subjects: A Review of Seventh Revision. Journal of Nepal Health Research Council, 17(4), 548-552. https://doi.org/10.33314/jnhrc.v17i4.1042

766 Shrikrishna, D., Patel, M., Tanner, R. J., Seymour, J. M., Connolly, B. A., Puthucheary, Z. A., 767 ... Hopkinson, N. S. (2012). Quadriceps wasting and physical inactivity in patients with COPD. European Respiratory Journal, 40(5), 1115-1122. https://doi.org/10.1183/09031936.00170111

770 Snijders, T., Wall, B. T., Dirks, M. L., Senden, J. M. G., Hartgens, F., Dolmans, J., ... Van 771 Loon, L. J. C. (2014). Muscle disuse atrophy is not accompanied by changes in skeletal muscle satellite cell content. Clinical Science, 126(8), 557-566. https://doi.org/10.1042/CS20130295

St. Andre, M., Johnson, M., Bansal, P. N., Wellen, J., Robertson, A., Opsahl, A., ... Owens, J. 

(2017). A mouse anti-myostatin antibody increases muscle mass and improves muscle strength and contractility in the mdx mouse model of Duchenne muscular dystrophy and its humanized equivalent, domagrozumab (PF-06252616), increases muscle volume in cynomolgus monkeys. Skeletal Muscle, 7(1). https://doi.org/10.1186/s13395-017-0141-y

Suetta, C., Frandsen, U., Mackey, A. L., Jensen, L., Hvid, L. G., Bayer, M. L., ... Kjaer, M. (2013). Ageing is associated with diminished muscle re-growth and myogenic precursor cell expansion early after immobility-induced atrophy in human skeletal muscle. Journal of Physiology, 591(15), 3789-3804. https://doi.org/10.1113/jphysiol.2013.257121

Swallow, E. B., Reyes, D., Hopkinson, N. S., Man, W. D. C., Porcher, R., Cetti, E. J., ... Polkey, M. I. (2007). Quadriceps strength predicts mortality in patients with moderate to severe chronic obstructive pulmonary disease. Thorax, 62(2), 115-120. https://doi.org/10.1136/thx.2006.062026

Thériault, M.-E., Paré, M.-È., Lemire, B. B., Maltais, F., \& Debigaré, R. (2014). Regenerative defect in vastus lateralis muscle of patients with chronic obstructive pulmonary disease. Respiratory Research, 15(1), 35. https://doi.org/10.1186/1465-9921-15-35

Thériault, M. E., Paré, M. Ė., Maltais, F., \& Debigaré, R. (2012). Satellite cells senescence in limb muscle of severe patients with COPD. PLoS ONE, 7(6), e39124. https://doi.org/10.1371/journal.pone.0039124

Vogelmeier, C. F., Criner, G. J., Martínez, F. J., Anzueto, A., Barnes, P. J., Bourbeau, J., ... Agustí, A. (2017). Global Strategy for the Diagnosis, Management, and Prevention of Chronic Obstructive Lung Disease 2017 Report: GOLD Executive Summary. Archivos de Bronconeumologia, 53(3), 128-149. https://doi.org/10.1016/j.arbres.2017.02.001

Vogiatzis, I., Simoes, D. C. M., Stratakos, G., Kourepini, E., Terzis, G., Manta, P., ... Zakynthinos, S. (2010). Effect of pulmonary rehabilitation on muscle remodelling in cachectic patients with COPD. The European Respiratory Journal, 36(2), 301-310. 
800

801

802

803

804

805

806

807

808

809

810

811

812

813

814

815

816

817

818

819

820

821

822

823

824

https://doi.org/10.1183/09031936.00112909

Vogiatzis, I., Stratakos, G., Simoes, D. C. M., Terzis, G., Georgiadou, O., Roussos, C., \& Zakynthinos, S. (2007). Effects of rehabilitative exercise on peripheral muscle TNF $\alpha$, IL6, IGF-I and MyoD expression in patients with COPD. Thorax, 62(11), 950-956. https://doi.org/10.1136/thx.2006.069310

Walsh, F. S., \& Celeste, A. J. (2005). Myostatin: A modulator of skeletal-muscle stem cells. Biochemical Society Transactions, 33(6), 1513-1517. https://doi.org/10.1042/BST20051513

Wurtzel, C. N. W., Gumucio, J. P., Grekin, J. A., Khouri, R. K., Russell, A. J., Bedi, A., \& Mendias, C. L. (2017). Pharmacological inhibition of myostatin protects against skeletal muscle atrophy and weakness after anterior cruciate ligament tear. Journal of Orthopaedic Research, 35(11), 2499-2505. https://doi.org/10.1002/jor.23537

Yin, H., Price, F., \& Rudnicki, M. A. (2013). Satellite cells and the muscle stem cell niche. Physiological Reviews, 93(1), 23-67. https://doi.org/10.1152/physrev.00043.2011 


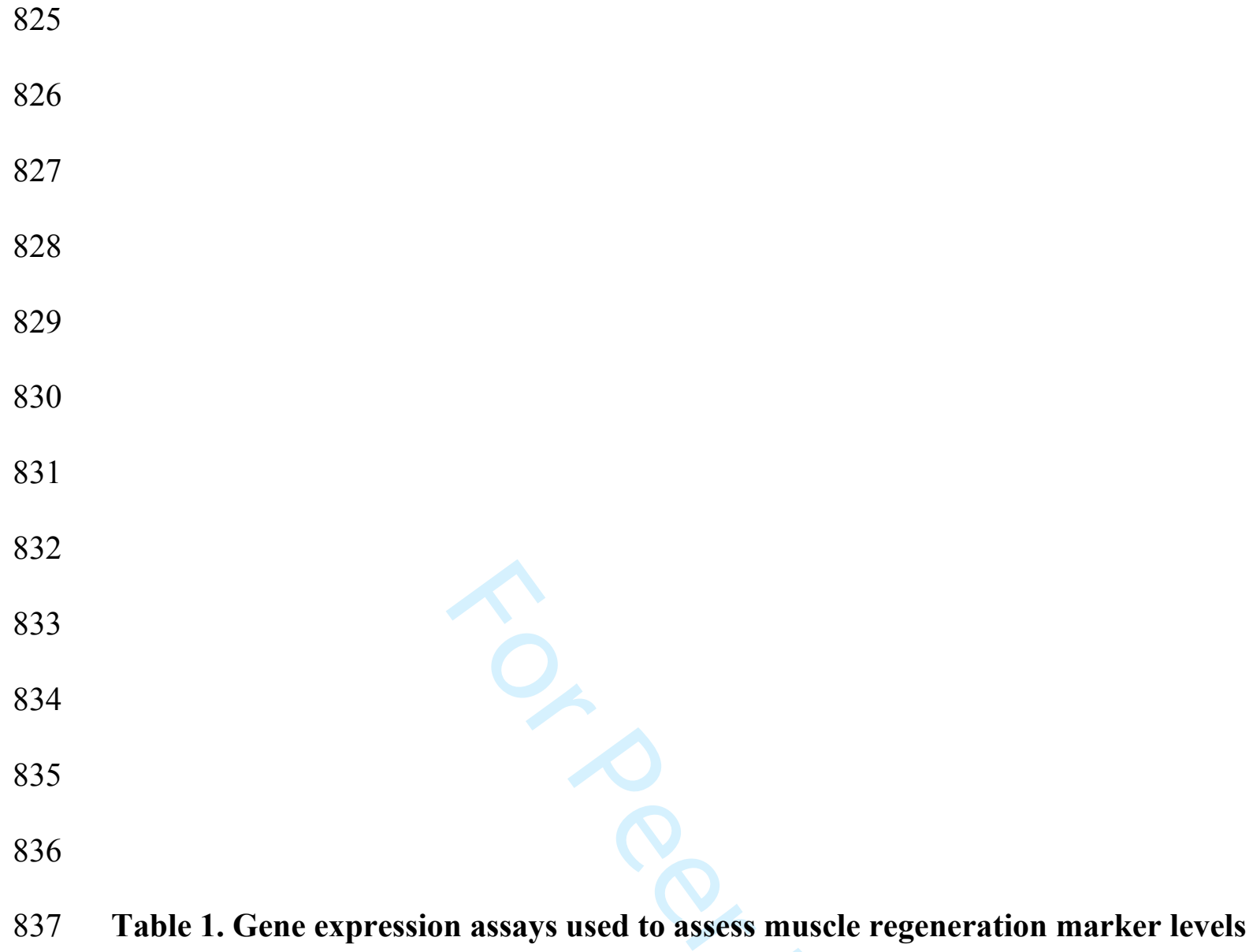




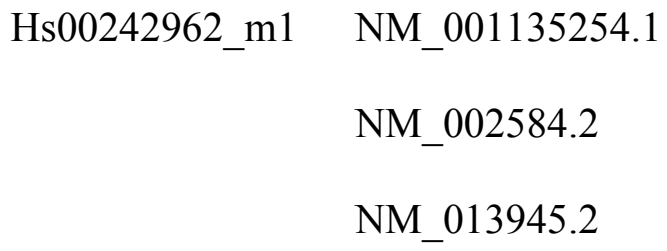

839 Abbreviations: ID, identification; Hs, homo sapiens; m1, multi-exonic gene assay does not detect genomic DNA; 840 g1, multi-exonic gene assay may detect genomic DNA if present in the sample; NM, mRNA RefSeq database 841 category; PAX3, paired box gene 3; PAX7, paired box gene 7; MYF5, Myogenic factor 5; MYOD1, myogenic 842 differentiation 1; MYOG, myogenin; MYH7, myosin heavy chain 7; MYH2, myosin heavy chain 2; MYH1, 843 myosin heavy chain 1; and GAPDH, glyceraldehyde-3-phosphate dehydrogenase. 


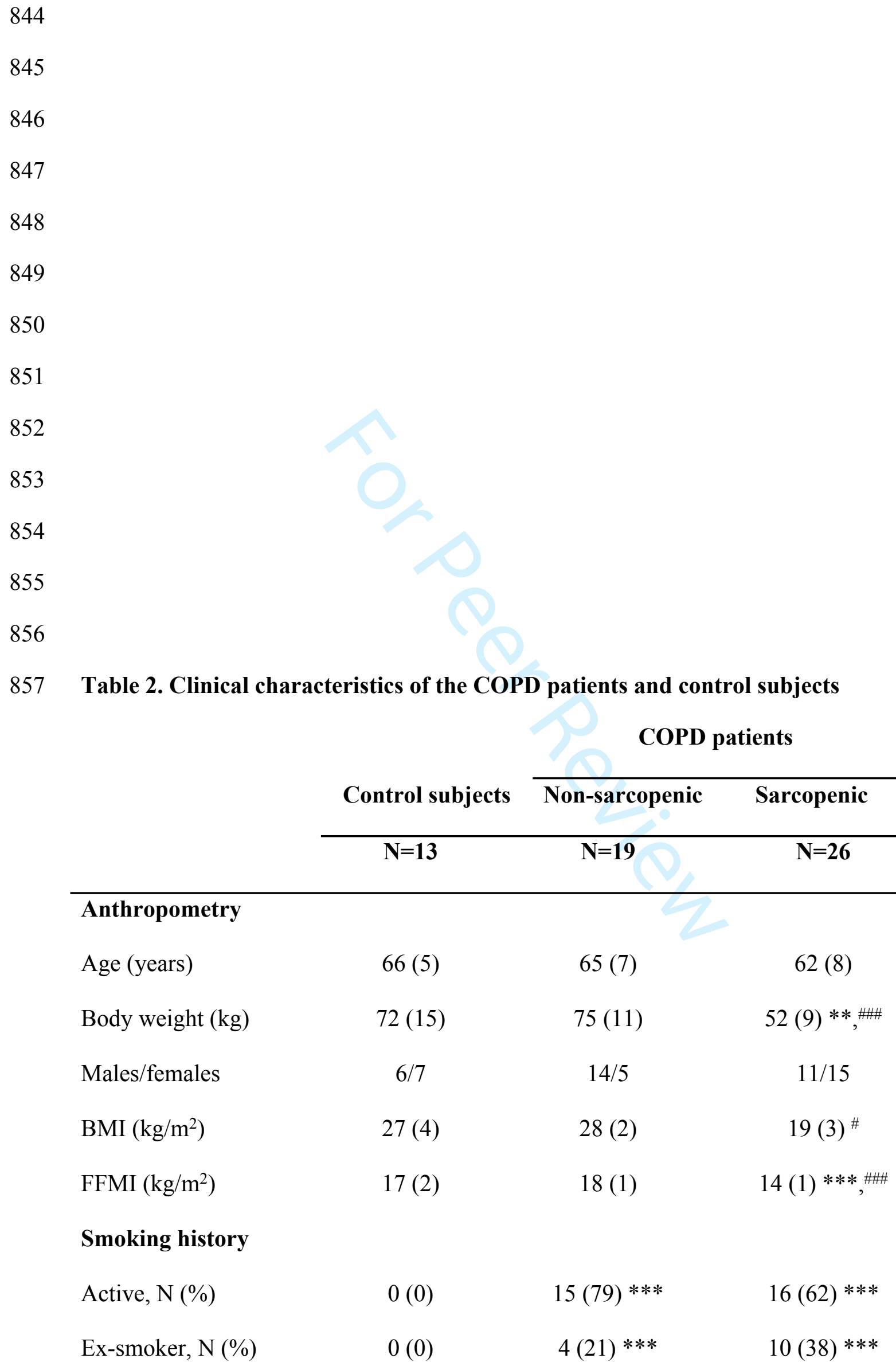

$18(1)$

14 (1) ***,\#\#

\section{Smoking history}

Active, N (\%)

$0(0)$

$15(79) * * *$

$16(62) * * *$

Ex-smoker, N (\%)

0 (0)

$4(21) * * *$

$10(38) * * *$ 


\begin{tabular}{|c|c|c|c|}
\hline Never smoker, N (\%) & $13(100)$ & $0(0) * * *$ & $0(0) * * *$ \\
\hline Packs-year & $0(0)$ & $61 * * *$ & $55 * * *$ \\
\hline \multicolumn{4}{|l|}{ Lung function testing } \\
\hline FEV1, \% predicted & $97(14)$ & $36(11) * * *$ & $34(11) * * *$ \\
\hline FVC, \% predicted & $98(12)$ & $67(15) * * *$ & $70(16) * * *$ \\
\hline $\mathrm{FEV}_{1} / \mathrm{FVC}$ & $76(6)$ & $42(10) * * *$ & $38(12) * * *$ \\
\hline $\mathrm{RV}, \%$ predicted & $112(14)$ & $185(43) * * *$ & $224(52) * * *, \#$ \\
\hline TLC, $\%$ predicted & $97(7)$ & $108(14)$ & $122(18) * * *, \#$ \\
\hline RV/TLC & $43(9)$ & $61(9) * * *$ & $65(8) * * *$ \\
\hline DLco, $\%$ predicted & $91(6)$ & $46(16) * * *$ & $35(13) * * *$ \\
\hline $\mathrm{KCO}, \%$ predicted & $93(19)$ & $49(16) * * *$ & $40(14) * * *$ \\
\hline $\mathrm{PaO}_{2}(\mathrm{KPa})$ & NA & $9.4(2.0)$ & $8.6(4.0)$ \\
\hline $\mathrm{PaCO}_{2}(\mathrm{KPa})$ & NA & $5.5(0.5)$ & $5.8(1.0)$ \\
\hline
\end{tabular}

Exercise capacity

and muscle function

$\begin{array}{lccc}\mathrm{VO}_{2} \max (\% \text { pred}) & 120(32) & 59(18) * * * & 54(24) * * * \\ \text { 6-min walking distance (m) } & 523(55) & 421(79) * * & 443(64) * * \\ \text { QMVC (Kg) } & 42(13) & 40(12) & 31(7) * * \text {, } \\ \text { QMVC (Kg)/FFM (Kg) } & 0.9(0.1) & 0.8(0.2) & 0.8(0.2)\end{array}$

Blood parameters

$\begin{array}{lccc}\text { Albumin }(\mathrm{g} / \mathrm{dL}) & 4.6(0.2) & 4.5(0.3) & 4.6(0.2) \\ \text { Total proteins }(\mathrm{g} / \mathrm{dL}) & 7.1(0.3) & 7.0(0.4) & 7.1(0.6) \\ \text { CRP }(\mathrm{mg} / \mathrm{dL}) & 0.3(0.3) & 0.5(0.3) & 0.3(0.3) \\ \text { Fibrinogen }(\mathrm{mg} / \mathrm{dL}) & 355(69) & 469(87) * * & 418(76) * \\ \text { GSV }(\mathrm{mm} / \mathrm{h}) & 10(7) & 17(13) & 10(11)\end{array}$


858

859

860

861

862

863

864

865

866

867

868

869

870

871

872

Values are expressed as mean (standard deviation).

Abbreviations: COPD, chronic obstructive pulmonary disease; N, number of patients; m, meters; BMI, body mass index; FFMI, fat-free mass index; FFM, fat-free mass, $\mathrm{kg}$, kilograms; $\mathrm{FEV}_{1}$, forced expiratory volume in one second; pred, predicted; FVC, forced vital capacity; RV, residual volume; TLC, total lung capacity; DLco, carbon monoxide transfer; $\mathrm{KCO}$, Krough transfer factor; $\mathrm{PaO}_{2}$, arterial oxygen partial pressure; $\mathrm{PaCO}_{2}$, arterial carbon dioxide partial pressure; $\mathrm{VO}_{2}$ peak, peak exercise oxygen uptake; QMVC, quadriceps maximum voluntary contraction; QMVC/FFM, quadriceps maximum voluntary contraction/fat-free mass; g, grams; dL, deciliter; mg, miligrams.; CRP, C-reactive protein; GSV, globular sedimentation velocity; mm, millimeters; h, hour. Statistical significance: *, p $<0.05, * *, p<0.01, * * *, p<0.001$ between any of the groups of COPD patients and the control subjects; \#, $<<0.05$, \#,, $\mathrm{p}<0.01$, \#\#, $\mathrm{p}<0.001$ between sarcopenic and non-sarcopenic COPD patients.

Table 3. Fiber type characteristics of the vastus lateralis in the study subjects

\section{COPD patients}

\begin{tabular}{lccc} 
& Control subjects & Non-sarcopenic & Sarcopenic \\
\hline Fiber Type I proportion (\%) & $33.0(5.9)$ & $28.7(13.2)$ & $26.6(9.4)^{*}$ \\
Fiber type II proportion (\%) & $65.2(5.6)$ & $64.3(13.7)$ & $63.0(10.5)$ \\
Hybrid fiber proportion (\%) & $1.8(1.7)$ & $6.9(4.1)^{* *}$ & $10.3(6.7)^{* * *}$, \\
Type I Fibers CSA, $\mu \mathrm{m}^{2}$ & $3589(1260)$ & $2678(540)^{*}$ & $2085(475)^{* * *}$ \\
Type II Fibers CSA, $\mu \mathrm{m}^{2}$ & $2800(1322)$ & $2819(851)$ & $1503(395)^{* *}, \ldots \#$ \\
Hybrid fibers CSA, $\mu \mathrm{m}^{2}$ & $2777(1534)$ & $2608(910)$ & $2042(827)^{* * *}, \#$ \\
\hline
\end{tabular}

873 Mean values and standard deviation of the proportions and sizes (cross-sectional areas) in the VL of both groups 874 of COPD patients and the control subjects. Definition of abbreviations: N, sample size; CSA, cross sectional 875 area. 
876 Statistical significance: ${ }^{*}, \mathrm{p}<0.05,{ }^{*}, \mathrm{p}<0.01$ and $* * *, \mathrm{p}<0.001$ between any of the groups of COPD patients 877 and the control subjects; ${ }^{\#}, \mathrm{p}<0.05,{ }^{\#} \mathrm{p}<0.01$ between sarcopenic and non-sarcopenic COPD patients. 878 879 880 881 882 883 884 885 886 887 888 889 Table 4A. Significant correlations of the study variables among all the study COPD 890 patients

$\begin{array}{lllllll}\text { FEV }_{1} / \text { FVC } & \text { FEV }_{1} & \text { DL }_{\text {CO }} & \text { KCO } & \text { FFMI } & \text { QMVC } & \text { CRP }\end{array}$

TUNEL

Abnormal fraction

Internal nuclei

$$
\begin{aligned}
& \mathrm{r}=0.432 \\
& \mathrm{P}=0.019 \\
& \mathrm{r}=-0.470 \\
& \mathrm{P}=0.010 \\
& \mathrm{r}=-0.367 \\
& \mathrm{P}=0.036
\end{aligned}
$$

Fiber Type I \% $\quad r=0.523 \quad r=0.418 \quad r=0.543$ 


$$
\mathrm{P}=0.003 \quad \mathrm{P}=0.021 \quad \mathrm{P}=0.003
$$

Fiber Type II \% $\quad r=-0.428 \quad r=-0.444 \quad r=-0.467$

$$
\mathrm{P}=0.003 \quad \mathrm{P}=0.007 \quad \mathrm{P}=0.006
$$

Type I Fibers CSA

$$
\begin{array}{lll}
\mathrm{r}=0.460 & \mathrm{r}=0.444 & \mathrm{r}=0.493 \\
\mathrm{P}=0.018 & \mathrm{P}=0.020 & \mathrm{P}=0.007
\end{array}
$$

Type II Fibers CSA

$$
\begin{aligned}
& r=0.673 \\
& P=0.000
\end{aligned}
$$

Hybrid fibers CSA

$$
\mathrm{r}=0.415
$$$$
\mathrm{P}=0.018
$$

Pax-7+/Myf-5+

In the table, units have been omitted for the sake of clarity, as they are already described in the corresponding

892 figures and tables. COPD, chronic obstructive pulmonary disease; FEV1, forced expiratory volume in 1 s; FVC,

893 forced vital capacity; DLco, carbon monoxide transfer; KCO, Krough transfer factor; FFMI, fat-free mass index;

894 QMVC, quadriceps maximum voluntary contraction; CRP, C-reactive protein; CSA, cross sectional area.

895

896

897

898

899

900

901

902

903

904

905 


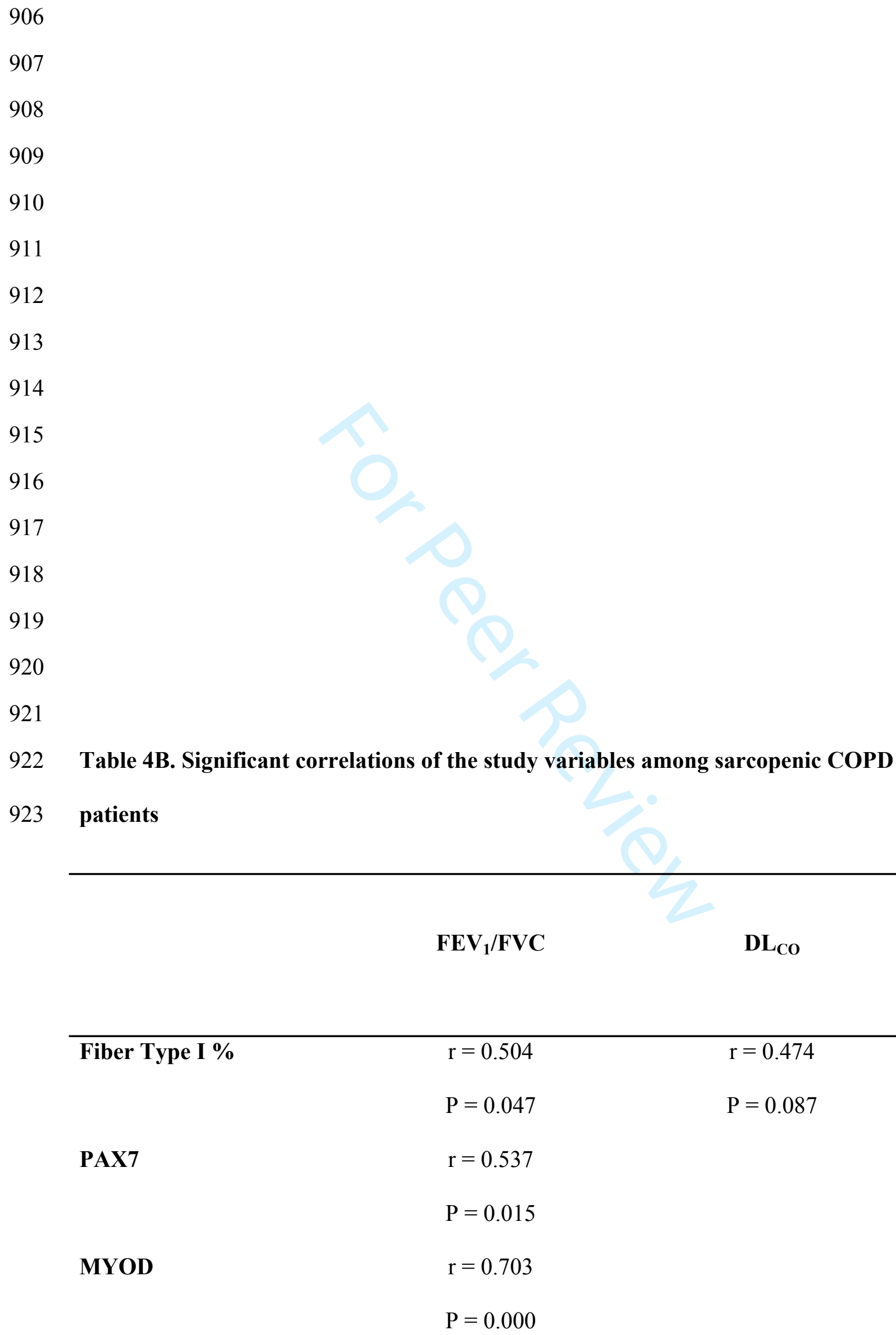


924 For the sake of clarity in the table, units have been omitted, as they are already being shown in the corresponding

925 figures and tables. COPD, chronic obstructive pulmonary disease; FEV1, forced expiratory volume in $1 \mathrm{~s}$; FVC,

926 forced vital capacity; DLco, carbon monoxide transfer; CSA, cross sectional area.

927

928

929

930

931

932

933

934

935

936

937

938

John Wiley \& Sons, Inc. 


\section{FIGURE LEGENDS}

940 Figure 1: (a) Representative images of VL cross-sectional histological preparations. 941 Myofibers positively stained for slow-twitch antibody appear in brown color in the left panels. 942 Myofibers positively stained for fast-twitch antibody appear in brown color in the right 943 panels. Hybrid myofibers are positively stained for slow-twitch and fast-twitch antibodies 944 (black arrows). (b) Mean values and standard deviation of muscle abnormalities: as measured 945 by total abnormal fraction and proportions of internal nuclei and inflammatory cells identified 946 in the VL of control subjects (white bars) and in both non-sarcopenic (grey bars) and 947 sarcopenic COPD patients (black bars). Statistical significance: ${ }^{*} \mathrm{p} \leq 0.05, * * \mathrm{p} \leq 0.01, * * * \mathrm{p} \leq$ 9480.001 between any of the COPD patient groups and the control subjects; ${ }^{*} \mathrm{p} \leq 0.05$ between 949 sarcopenic and non-sarcopenic COPD patients.

951 Figure 2: (a) Representative images of TUNEL-positively stained nuclei (brown, black 952 arrows) and TUNEL-negative nuclei (green, dotted arrows) in the VL. (b) Mean values and 953 standard deviation of the percentage of positively stained nuclei for the TUNEL assay in the 954 VL of the control subjects (white bars), non-sarcopenic COPD patients (grey bars) and 955 sarcopenic COPD patients (black bars). Statistical significance: ***p $\leq 0.001$ between any of 956 the groups of COPD patients and the control subjects.

957

958 Figure 3: (a) Mean values and standard deviation of Pax-7+/Myf-5- (quiescent), Pax-7+/Myf$9595+$ (activated) and total satellite cell counts per myofiber in the VL of control subjects (white 960 bars) and in both non-sarcopenic COPD patients (grey bars) and sarcopenic COPD patients 961 (black bars). Statistical significance: ${ }^{*} p \leq 0.05, * * p \leq 0.01$ between any of the groups of

962 COPD patients and the control subjects. (b) Representative images of immunofluorescence 963 staining of DAPI (left panels), Pax-7 (middle-left panels), Myf-5 (middle-right panels) and 
964 cells positively stained for both Pax-7 and Myf-5 markers (right panels) in muscles of control 965 subjects and in both non-sarcopenic and sarcopenic COPD patients. Triangle arrows indicate 966 Pax-7 positive cells (quiescent satellite cells) and thin arrows indicate double-stained nuclei 967 for both Pax-7 and Myf-5 positive cells (activated satellite cells).

968

969 Figure 4: (a) Mean values and standard deviation (relative expression) of genes of muscle 970 structure and regeneration in the VL of the control subjects (white bars), non-sarcopenic 971 COPD (grey bars) and sarcopenic COPD patients (black bars). Statistical significance: ${ }^{*} \mathrm{p} \leq$ $9720.05, * * \mathrm{p} \leq 0.01, * * * \mathrm{p} \leq 0.001$ between any of the groups of COPD patients and the control 973 subjects. (b) Mean values and standard deviation of myostatin protein, measured in optical 974 densities (OD) using arbitrary units (a.u.) in the VL of the control subjects (white bars) and in 975 both non-sarcopenic (grey bars) and sarcopenic COPD patients (black bars). Statistical 976 significance: ${ }^{* *} \mathrm{p} \leq 0.01$ between sarcopenic COPD patients and the control subjects; ${ }^{*} \mathrm{p} \leq 0.05$ 977 between sarcopenic and non-sarcopenic COPD patients. (c) Representative images of VL 978 cross-sectional histological preparations. Myostatin protein appears in brown color. 979 


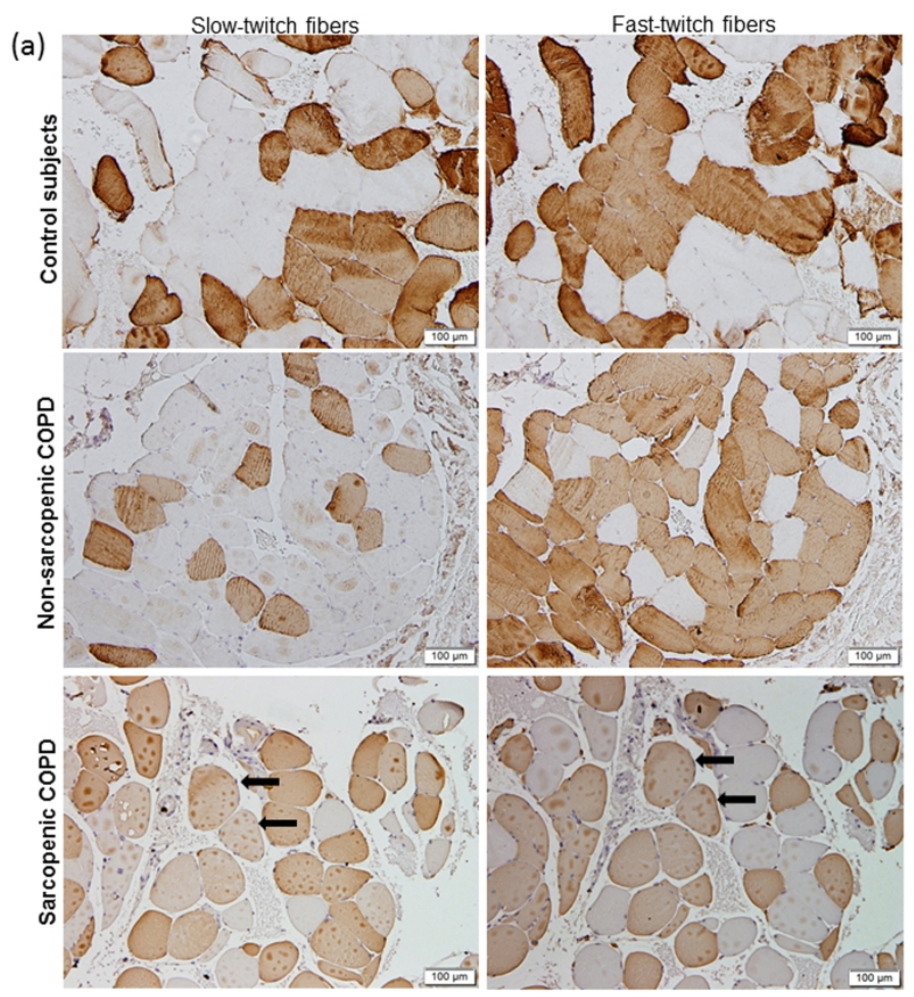

FIGURE 1A

$254 \times 190 \mathrm{~mm}$ (300 x 300 DPI)

John Wiley \& Sons, Inc. 
(b)

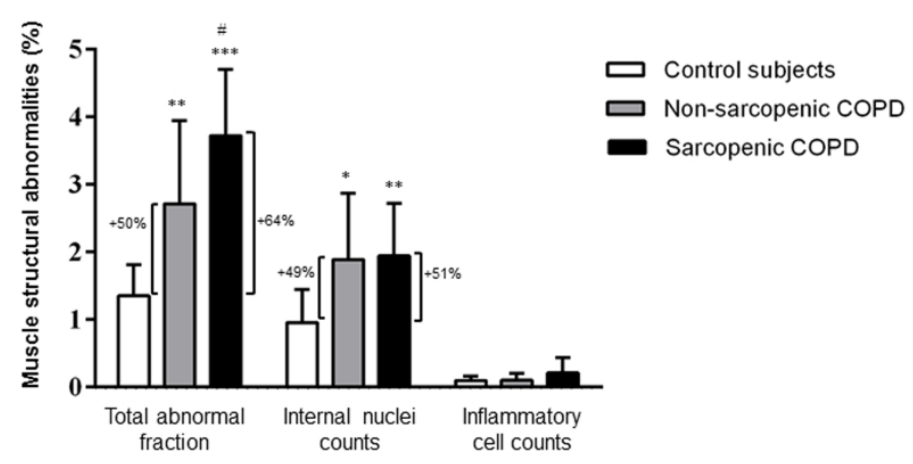

FIGURE 1B

$254 \times 190 \mathrm{~mm}(300 \times 300$ DPI)

John Wiley \& Sons, Inc. 
(a)

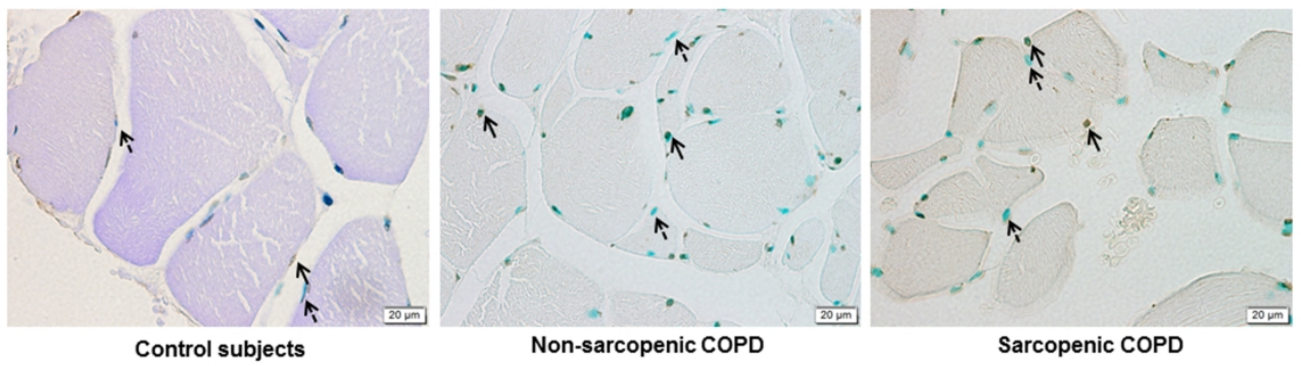

FIGURE 2A

$254 \times 190 \mathrm{~mm}(300 \times 300 \mathrm{DPI})$

John Wiley \& Sons, Inc. 


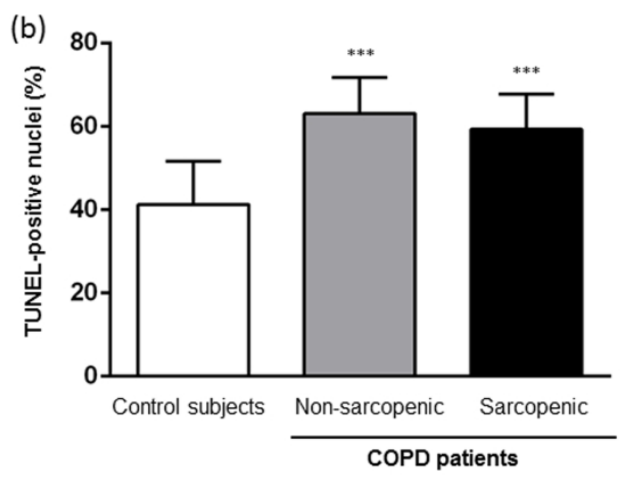

FIGURE 2B

$254 \times 190 \mathrm{~mm}(300 \times 300$ DPI)

John Wiley \& Sons, Inc. 


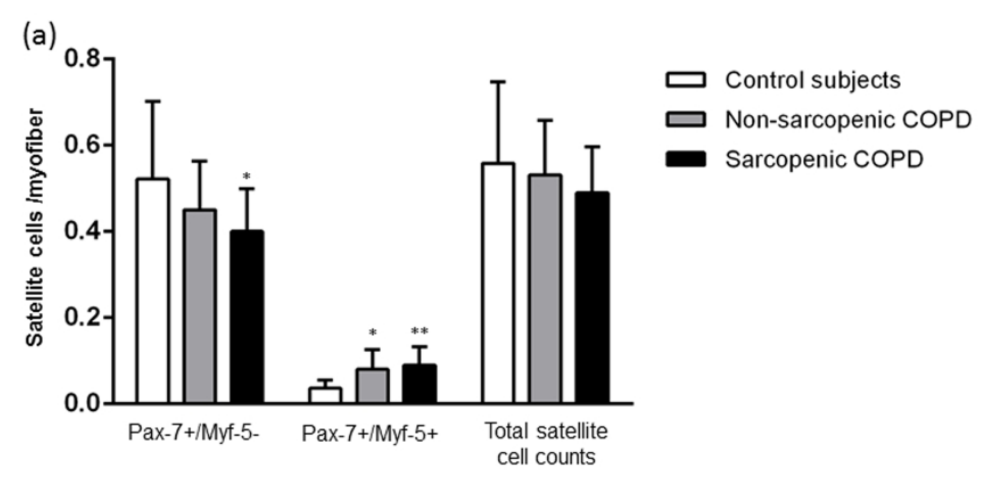

FIGURE 3A

$254 \times 190 \mathrm{~mm}(300 \times 300 \mathrm{DPI})$

John Wiley \& Sons, Inc. 
(b)

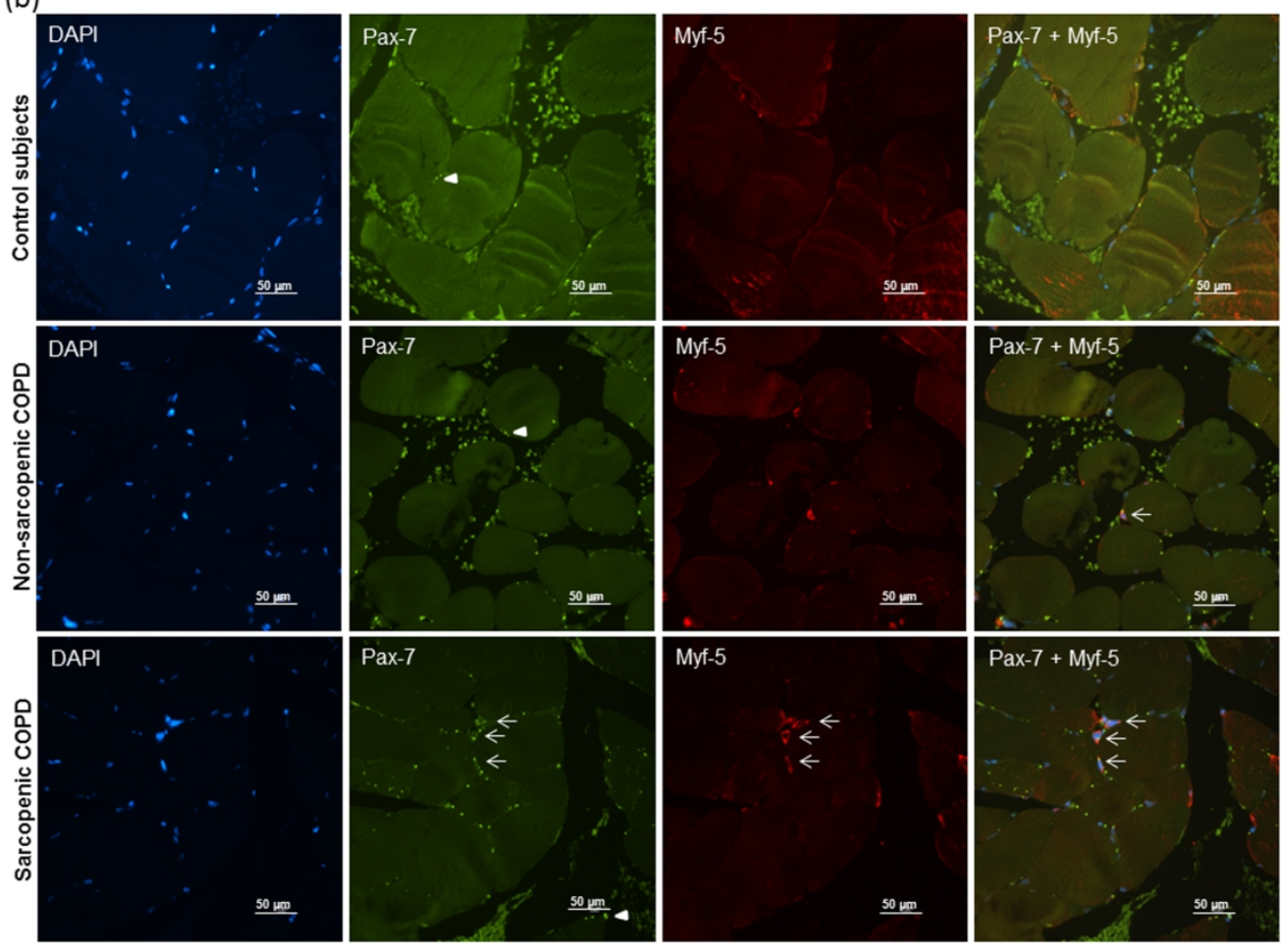

FIGURE 3B

$254 \times 190 \mathrm{~mm}(300 \times 300$ DPI)

John Wiley \& Sons, Inc. 
(a)

\section{FIGURE 4A}

$254 \times 190 \mathrm{~mm}(300 \times 300 \mathrm{DPI})$ 


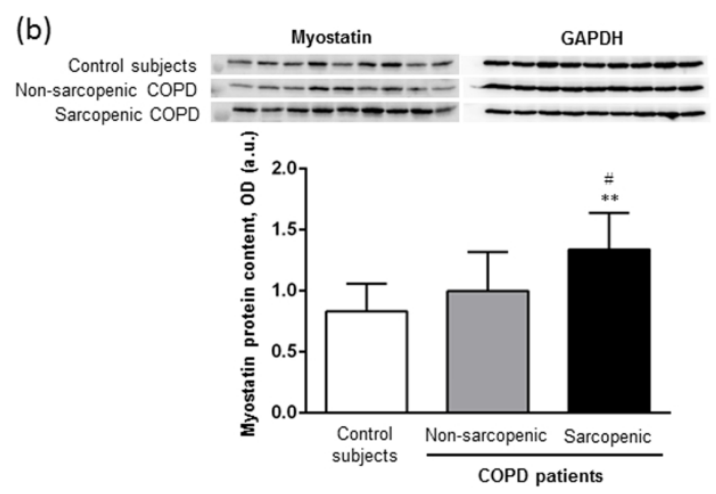

FIGURE 4B

$254 \times 190 \mathrm{~mm}(300 \times 300 \mathrm{DPI})$

John Wiley \& Sons, Inc. 
(c)

\section{FIGURE 4C}

$254 \times 190 \mathrm{~mm}(300 \times 300 \mathrm{DPI})$

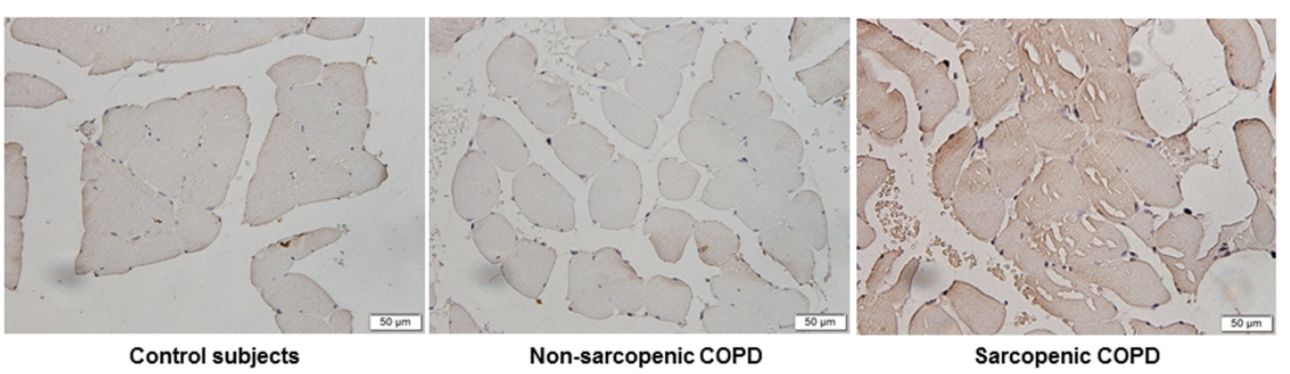

John Wiley \& Sons, Inc. 